\title{
Metal-Air Battery Assessment
}

R. K. Sen

S. L. Van Voorhees

I. Ferrel

May 1988

Prepared for

Office of Energy Storage and Distribution

Conservation and Renewable Energy

the U.S. Department of Energy

under Contract DE-AC06-76RLO 1830

Pacific Northwest Laboratory

Operated for the U.S. Department of Energy

by Battelle Memorial Institute 


\title{
DISCLAIMER
}

This report was prepared as an account of work sponsored by an agency of the United States Government. Neither the United States Government nor any agency thereof, nor Battelle Memorial Institute, nor any or their employees, makes any warranty, expressed or implied, or assumes any legal liability or responsibility for the accuracy, completeness, or usefuiness of any information, apparatus, product, or process disclosed, or represents that its use would not infringe privately owned rights. Reference herein to any specific commercial product, process, or service by trade name, trademark, manufacturer, or otherwise does not necessarily constitute or imply its endorsement, recommendation, or favoring by the United States Government or any agency thereof, or Battelle Memorial Institute. The views and opinions of authors expressed herein do not necessarily state or refiect those of the United States Government or any agency thereof, or Battelle Memorial Institute.

\author{
PACIFIC NORTHWEST LABORATORY \\ operated by \\ BATTELLE MEMORIAL INSTITUTE \\ for the \\ UNITED STATES DEPARTMENT OF ENERGY \\ under Contract DE-ACO6-76RLO 1830
}

\begin{tabular}{|c|c|}
\hline Printe & s of America \\
\hline & \\
\hline National Jechr & ation Service \\
\hline United States $D$ & of Commerce \\
\hline $\begin{array}{r}5285 \\
\text { Springfi }\end{array}$ & $\begin{array}{l}\text { ad } \\
22161\end{array}$ \\
\hline NTI & \\
\hline & \\
\hline & \\
\hline & Price \\
\hline Pages & Codes \\
\hline $001-025$ & A02 \\
\hline $026-050$ & A03 \\
\hline $051-075$ & $A 04$ \\
\hline $076-100$ & $A 05$ \\
\hline $101-125$ & $A 06$ \\
\hline $126-150$ & $A 07$ \\
\hline $151-175$ & $A D B$ \\
\hline $176-200$ & $A 09$ \\
\hline $201-225$ & A010 \\
\hline $226-250$ & A011 \\
\hline 251.275 & A012 \\
\hline $276-300$ & A013 \\
\hline
\end{tabular}


METAL-AIR BATTERY ASSESSMENT

Technical Contributors: Rajat K. Sen - PNL Seth L. Van Voorhees - PNL $T$. Ferrel - Consultant

May 1988

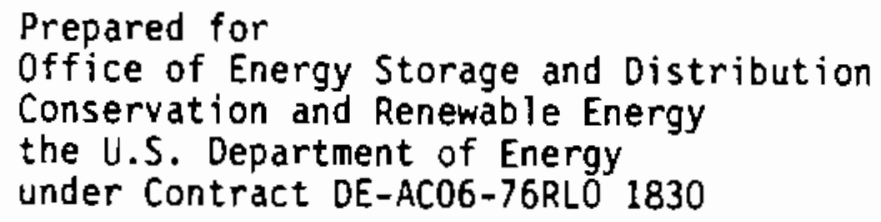

Pacific Northwest Laboratory

Richland, Washington 99352 


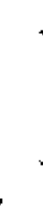




\section{EXECUTIVE SUMMARY}

The U.S. Department of Energy has supported the development of metal-air batteries for electric vehicle application due to their potential high energy density, rapid refuelability, long range and ambient temperature operation. Zinc-air, aluminum-air and iron-air are considered the viable candidates for the electric vehicle application. This report attempts to evaluate the present technical status of these three battery systems and assess their potential for eiectric vehicle application.

This report identifies the mechanically rechargeable aluminum-air system and the circulating slurry zinc-air system as having good potential to power an electric vehicle. Although the electric to electric energy efficiency of these batteries is lower than other advanced batteries, such as sodium-sulfur, the potential of long range, rapid refuelability and per:ormance warrants the continued development of the metal-air battery technology. The coal to road efficiency of the two above-mentioned batteries is expected to be better than the efficiency of an ICE engine operating on synthetic fuels.1 The aluminumair and the circulating slurry zinc-air systems are quite complex and the reliability and vehicle packaging issues could be significant. Attention must be given to these factors during the research effort. The air cathodes are the key factor in determining the life cycle cost of the two systems. Lower cost and longer life are required. Research to accomplish this goal should continue.

Over the last four years good progress has been made in component research on the aluminum-air battery with DOE support. The demonstration of the technical feasibility of this battery requires the operation of this battery with its electrolyte management system. This has not yet been attempted. Based on the present status of the component research, it is strongly recommended that an integrated operation of the system in the laboratory scale be undertaken.

Research on the circulating slurry zinc-air battery has been initiated with DOE support in FY 1986. The key technical issues have been identified by the Technology Base Research Lead Center and the contractor. Not much experimental data on system performance is presently available. 
Research on bi-functional electrodes is also recommended since a breakthrough in this technology could make the iron-air battery a very viable candidate for electric vehicles, especially those involving fleet operation. 


\section{CONTENTS}

EXECUTIVE SUMMARY $\ldots \ldots \ldots \ldots \ldots \ldots \ldots \ldots$

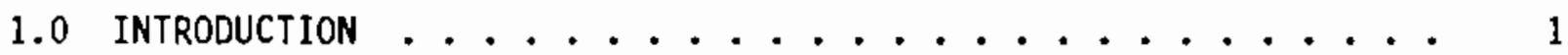

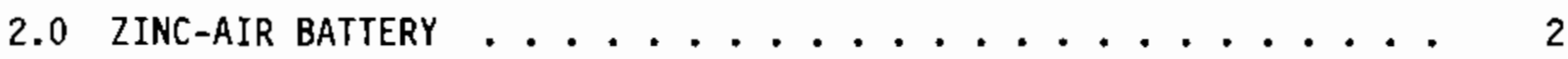

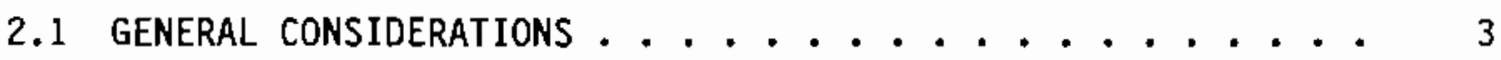

2.2 CONVENTIONAL SECONDARY SYSTEMS .................... 3

2.3 MeCHANICALly ReCHARgEABLE SYSTEMS ........... 6

2.4 CIRCULATING ELECTROLYTE SYSTEMS ........... 7

2.5 CIRCULATING SLURRY SYSTEM . . . . . . . . . . . 12

3.0 ALUMINUM-AIR BATTERY $\ldots \ldots \ldots 23$

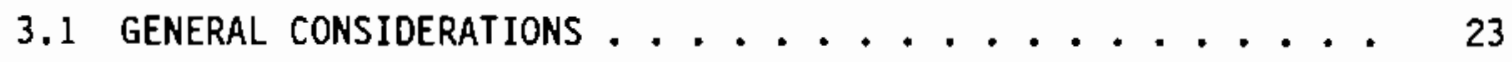

3.2 ALKALINE ELECTROLYTE ALUMINUM-AIR SYSTEM . . . . . . 25

3.2.1 THE BATTERY ................. 25

3.2 .2 THE ELECTROLYTE MANAGEMENT SYSTEM . . . . . . 28

3.3 PRESENT DEVELOPMENT STATUS . . . . . . . . . . . . 28

3.3 .1 BATTERY COMPONENTS ................. 30

3.3 .2 THE ALUMINUM-AIR BATTERY . . . . . . 38

3.3 .3 THE ELECTROLYTE MANAGEMENT SYSTEM . . . . . . . 44

4.0 IRON-AIR BATTERY . . . . . . . . . . . . . . . 49

4.1 GENERAL CONSIDERATIONS ...................... 49

4.2 PRESENT DEVELOPMENT STATUS . . . . . . . . . . . 50

4.2 .1 THE IRON ELECTRODE ............. 50

4.2 .2 THE BI-FUNCTIONAL AIR-ELECTRODE ........ 50

4.2 .3 THE BATTERY .................... 51

5.0 MONO/BI-FUNCTIONAL AIR ELECTRODES . . . . . . . . 55

5.1 THE AIR CATHODE ............................ 55 


\section{CONTENTS (contd)}

5.2 THE BI-FUNCTIONAL AIR-ELECTRODE . . . . . . . . 58

6.0 COMPARISON OF METAL-AIR BATTERY SYSTEMS . . . . . . . . . . . 61

7.0 SYSTEM DESIGN AND LIFE CYCLE COSTS . . . . . . . . . . . . 65

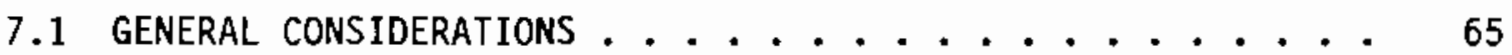

7.2 ALUMINUM-AIR SYSTEM .......................... 65

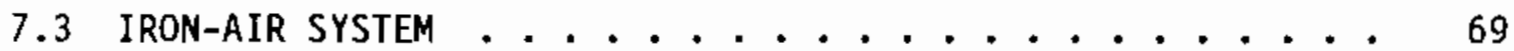

7.4 ZINC-AIR SYSTEM ....................... 72

7.5 GENERAL COST CONSIDERATIONS . . . . . . . . 74

8.0 CONCLUSIONS AND RECOMMENDATIONS . . . . . . . . . . . . 77

REFERENCES ........................ 81 


\section{FIGURES}

2.1 Recharging Schemes for Zinc-Air Batteries . . . . . . . . 4

2.2 Schematic of a Circulating Electrolyte Zinc-Air Battery . . . . 9

$2.3124 \mathrm{~V}$ Circulating Electrolyte Zinc-Air Battery . . . . . . . . 11

2.4 Schematic of a Circulating Slurry Zinc-Air Battery . . . . . 13

2.5 Zinc Utilization and Capacity Extension of Selected Type A and B Additives in $12 \mathrm{M} \mathrm{KOH} \mathrm{Zn} \mathrm{Powder} \mathrm{Slurry} \mathrm{.} \mathrm{.} \mathrm{.} \mathrm{.} \mathrm{.} \mathrm{.} 15$

2.6 Discharge Performance of a Zinc-Air Slurry Type Laboratory Cell at CGI . . . . . . . . . . . . 16

2.7 Overal1 View of the CGE Circulating Slurry Zinc-Air Battery . . . 17

2.8 Schematic of the GE Circulating Slurry Zinc-Air Battery . . . . 19

2.9 Discharge Performance of $\mathrm{Zn}$ Bead and Powder Slurry in $12 \mathrm{M}$ $\mathrm{KOH}+25 \mathrm{~g} / 1$ Silicate $+15 \mathrm{~g} / 1$ Sorbitol Using Either Air or Oxygen ......................

2.10 Current Efficiency vs Current Density Curves for the Electrodeposition of Metallic Zinc on a Stationary, Planar

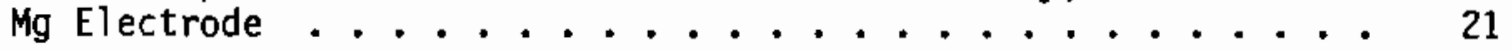

3.1 Schematic of an Alkaline Aluminum-Air Battery Systen . . . . . 26

3.2 The Alkaline Aluminum-Air Cell . . . . . . . . . . 29

3.3 Open Circuit Potential of Aluminum and Proprietary Aluminum Alloys in $\mathrm{NaOH}$ and $\mathrm{KOH} . . . . . . . .$.

3.4 Corrosion Rates of Aluminum and Proprietary Aluminum Alloys in $\mathrm{NaOH}$ and $\mathrm{KOH}$. . . . . . . . . . . .

3.5 Current Potential Curve of the Proprietary Alloy BDW in $\mathrm{NaOH}$ and $\mathrm{KOH}$. . . . . . . . . . . . . . 34

3.6 Drive Cycle Under Which the Air Cathodes are Tested . . . . . 37

3.7 Voltage as a Function of Drive Cycles for a Co(TMPP) Catalyzed Air Electrode at the Current Densities . . . . . . . 39

3.8 Carbon Black Electrode Performance . . . . . . . . . . 40

3.9 Improvements with Time in the Cycle Life of Air Cathodes for the Aluminum-Air Battery ................ 


\section{FIGURES (contd)}

3.10 Schematic of the Eltech Systems Corporation EL-2 Cell ..... 45

3.11 A Simplified Electrolyte Management System . . . . . . . . 46

4.1 Schematic of a Swedish National Development

Corporation Iron-Air Battery ............. 52

4.2 Charge-Discharge Performance of the SNDC Battery . . . . . 53

4.3 Power Characteristics of a Westinghouse Iron-Air Cell . . . . 54

5.1 Performance of a $\mathrm{Co}$ (TMPP) Catalyzed Norit Carbon Electrode

\section{TABLES}

1.1 Characteristics of Metal/Air Cells ............. 1

2.1 Specifications of the Sanyo 124v Zinc-Air Battery ....... 10

3.1 Expected Energy and Power Oensities from Neutral and Alkaline Electrolyte Aluminum-Air Batteries . . . . . . 24

3.2 Operating Data of the EL-2 Cell .............. 41

4.1 Module Characteristics of a Westinghouse Iron-Air Battery . . . . 51

6.1 Comparison of Metal-Air Batteries ............ 62

7.1 Aluminum-Air System Proposed Power and Energy Assumptions . . . 67

7.2 Aluminum-Air Battery: Estimated Annual costs . . . . . . . 68

7.3 Iron-Air Battery Characteristics . . . . . . . . . 70

7.4 Iron-Air Battery Cost Assumptions . . . . . . . . . 71

7.5 Iron-Air Battery Life Cycle Cost Assumptions . . . . . . . 74 


\subsection{INTRODUCTION}

Metal-air batteries involve the electrochemical coupling of a reactive metal anode to an air electrode. The reactive metal anode in the metal-air battery can be considered as a high energy fuel, which is being oxidized eiectrochemically by air. Several reactive metals can be used in metal-air batteries. Table 1.1 lists the characteristics of the metal-air battery as a function of various metal anodes. 2 One important characteristic to note is the very high theoretical energy density expected from some of these couples.

TABLE 1.1

Characteristics of Metal/Air Cells

\begin{tabular}{lcccc}
\hline $\begin{array}{c}\text { Metal } \\
\text { Anode }\end{array}$ & $\begin{array}{c}\text { Electrochemical } \\
\text { Equivalent of Metal } \\
\text { Ah/gm }\end{array}$ & $\begin{array}{c}\text { Theoretical } \\
\text { Cell Voltage* }\end{array}$ & $\begin{array}{c}\text { Theoretical } \\
\text { Specific Energy } \\
\text { Wh/gm }\end{array}$ & $\begin{array}{c}\text { Practical } \\
\text { Operating } \\
\text { Voltage }\end{array}$ \\
$\mathrm{Li}$ & 3.86 & 3.4 & 13 & 2.4 \\
$\mathrm{Ca}$ & 1.34 & 3.4 & 4.6 & 2.0 \\
$\mathrm{Mg}$ & 2.20 & 3.1 & 6.8 & 1.4 \\
$\mathrm{Al}$ & 2.98 & 2.7 & 8.1 & 1.6 \\
$\mathrm{Zn}$ & 0.82 & 1.6 & 1.3 & 1.2 \\
$\mathrm{Fe}$ & 0.96 & 1.3 & 1.2 & 1.0 \\
\hline
\end{tabular}

* Cell voltage with Oxygen Cathode

Metal/air batteries, either in the laboratory scale or large prototype forms, have been successfully operated with zinc, iron, lithium and aluminum. Magnesium/air 3 and calcium/air 4 batteries have been studied, but anode polarization, instability, parasitic corrosion, non-uniform dissolution as well as other problems have prevented their successful development.

The U.S. Department of Energy (DOE) is interested in metal/air batteries primarily for applications in electric vehicles, due to their potential high energy density, extended performance, rechargeability, and ambient temperature operation. Lithium/air batteries certainly meet these criteria. In fact, a 
$1.2 \mathrm{~kW}$ lithium/air battery has been constructed and operated successfully. 5,6 However, it is generally accepted that the limited availability and safety issues involved greatly reduce this battery's potential for electric vehicle application. (a) Thus zinc-air, aluminum/air and iron/air batteries are the most viable candidates for potential electric vehicle applications.

The objective of this report is to evaluate the present technical status of the zinc-air, aluminum/air and iron/air batteries and assess their potential for use in an electric vehicle. In addition, this report will outline proposed research and development priorities for the successful development of metalair batteries for electric vehicle application.

(a) Considerable work is in progress on lithium-air batteries for DOD applications under the sponsorship of DARPA. Not much data from this effort is available in the open literature to evaluate its potential. 


\subsection{ZINC-AIR BATTERIES}

\subsection{GENERAL CONSIDERATIONS}

The zinc-oxygen electrochemical system consists of a porous zinc anode, an air cathode and an electrolyte of 25-40\% potassium hydroxide. The overall cell reactions can be simplified as follows:

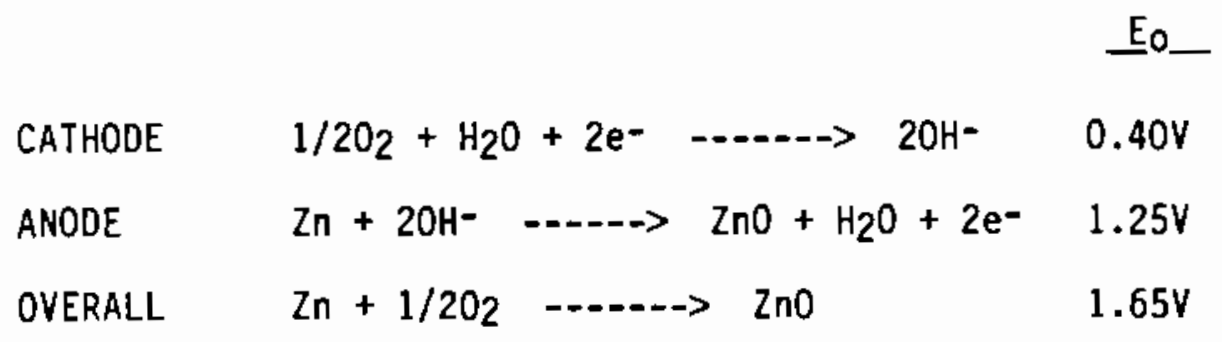

The capacity of the cell is directly proportional to the quantity of zinc.

As with most batteries, the zinc-air cell can be designed either as a primary or secondary battery. Primary zinc-air batteries have long been used for low drain, high capacity applications and are thrown away after the zinc charge in the battery is exhausted. Since these disposable type of design are impractical for an electric vehicle, they are not included in this report.

Secondary systems involve the regeneration of the $2 \mathrm{no}$ or zincate to zinc, which can then be reused in the zinc-air battery. This regeneration can be achieved either by mechanical or electrical recharging. Various schemes for accomplishing this objective in a zinc-air cell are shown in Figure 2.1.

The present status, future potential and the advantages/disadvantages of zinc-air batteries developed according to the schemes shown in Figure 2.1 are discussed in the following section.

\subsection{CONVENTIONAL SECONDARY SYSTEMS}

During discharge the solid zinc anode dissolves in the $\mathrm{KOH}$ electrolyte solution to form zincate. The electrochemical reaction products are then regenerated within the battery by the passage of electric current during the charging phase. For a zinc-air battery to operate in this mode, there is the need for a bi-functional oxygen electrode on which both the evolution and 
reduction of molecular oxygen can occur at low overpotential. Alternatively, a secondary zinc-air battery can be constructed which contains three electrodes in which oxygen is evolved on one electrode and dissolved at another.

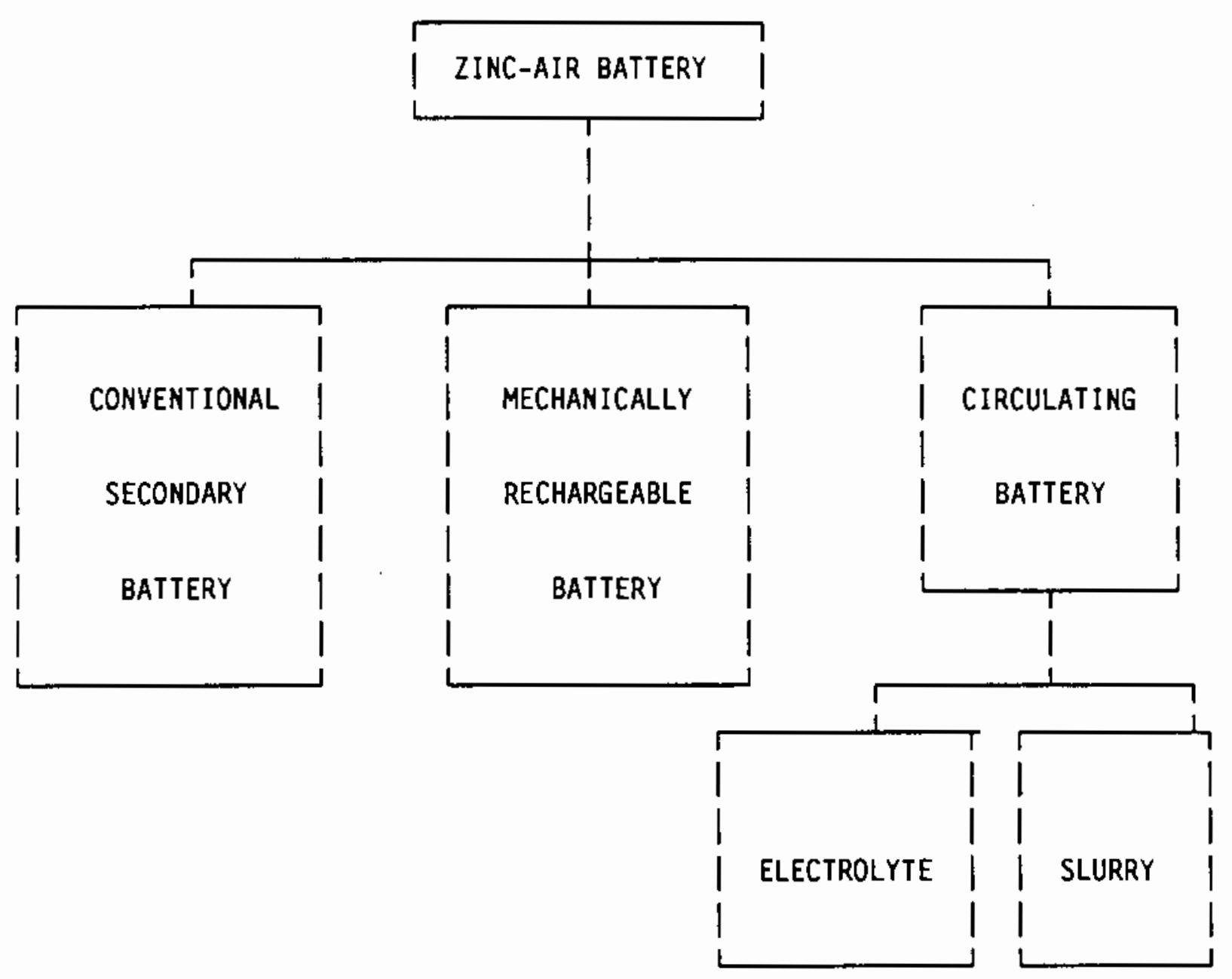

FIGURE 2.1 Recharging Schemes for Zinc-Air Batteries

A large body of literature exists on efforts to develop secondary zincair batteries, including several systems which have been developed for specific 
military applications.7 However, a cost-effective system with satisfactory performance for electric vehicle applications has not yet been developed.

Compagnie General d'Electricite (CGE) attempted to develop a secondary zinc-air battery using a bi-functional air-electrode, primarily for EV applications.8 12Ahr, 2.4amp cells were fabricated and tested. An interesting feature of the cell was the use of a three-dimensional reticulated current collector for the zinc electrode. This development reduced the problem associated with zinc electrode shape change during cycling and increased cycle life. Cycle life has been reported to be over 400 cycles, with a capacity of approximately $90 \%$. Specific energy of $77 \mathrm{Wh} / \mathrm{Kg}$ have been reported. Development work on this battery has been terminated, as the company decided to reduce their effort in advanced batteries.

Energy Research Corporation (ERC), developed a secondary, three electrode zinc/air battery for the US Army Electronic Command.9,10 It was based on the concept of using single, sealed cylindrical cells in which the active electrodes and stored oxygen was contained. The cylindrical cell container served as the pressure vessel for the stored oxygen. This system demonstrated a life capability of 200 charge-discharge cycles and an energy density of $132 \mathrm{wh} / \mathrm{kg}$. Although this type of battery was judged to be acceptable for the Army application, the use of the third electrode complicates the design and lowers the efficiency of the system.

Two major technical problems have limited the development of secondary zinc-air batteries for electric vehicle application. The first is associated with shape changes that the planar zinc electrode experiences on repeated cycling, which severely limits the cycle life of the battery. This problem is not unique to the zinc-air battery, but also has been evident with other secondary batteries employing zinc as an active electrode, e.g. nickel-zinc. To date the shape change of the zinc electrode limits the cycle life to less than 400 cycles. Considerable R\&D effort has been undertaken to understand the cause of the shape change associated with the zinc electrode and to develop methods to minimize this effect.

The second technical problem associated with the secondary zinc-air battery is the bi-functional air-electrode. A bi-functional air electrode must evolve oxygen during the charge cycle and reduce oxygen to $\mathrm{OH}^{-}$during 
the discharge cycle, with a minimum voltage penalty and long life. Westinghouse has been a primary developer of bi-functional air-electrode for the iron-air battery in the United States. 11

Most bi-functional air-electrodes under development use carbon or graphite as a substrate material. Corrosion of this substrate, particularly during the charging cycle, is severe, limiting the lifetime of the electrode. In addition, catalysts which promote both the evolution and the reduction of oxygen are not readily available. Thus overpotentials for the anodic and cathodic reactions are high, resulting in marginal performance of the air-electrode. The best electrodes have survived up to 500 cycles, whereas the target value of 1000 cycles is thought to be needed for electric vehicle application.

Research focused on understanding the relationship between corrosion and the carbon structure of the electrode has led to the development of new carbon materials containing "tailor-made" properties (ie. corrosion resistant high area graphitized carbon black with a functionalized surface for controlled wettability). ${ }^{12}$ These new materials show great potential in fabricating bifunctional air electrodes which are light, have an acceptable lifetime for electric vehicle application and are low cost.

\subsection{MECHAN1CALLY RECHARGEABLE SYSTEM}

This is a conventional primary battery. The planar zinc electrode is consumed during the discharge process, producing zincate in the $\mathrm{KOH}$ electrolyte solution. The discharged zinc anode and spent electrolyte are replaced periodicaliy. In a separate external system, zinc is replated from the spent electrolyte and both the zinc and the rejuvenated electrolyte are reused in the battery.

In the 1970s, General Motors demonstrated a $35 \mathrm{kwh}$, mechanically rechargeable zinc-air battery in a $1350 \mathrm{Kg}$ test bed vehicle.10 Technical problems associated with short activated life of the zinc anode, intermittent performance, and anode replacement problems thwarted the further development of this battery. Sanyo presently manufactures mechanically rechargeable zincair batteries ranging from 20-200 Ah at voltages from 1 to $12 \mathrm{v} .{ }^{13}$ These are designed as water activated reserve batteries which are also mechanically refuelable. The main advantages of the mechanically rechargeable system are: 
- Eliminates the need for bi-functional air-electrodes, thus effectively by-passing a key technical hurdle.

- Provides the option of rapid rechargeability, since the recharging process involves the replacement of the zinc anode and the electrolyte.

One of the inherent problems with these systems stems from the limited solubility of zinc in concentrated $\mathrm{KOH}$. As the solubility limit is approached the zincate ion begins to precipitate out of solution as hydrated $\mathrm{znO}$, drastically reducing the performance of the battery. Thus the solubility of zinc in the electrolyte effectively controls the capacity of the battery. In the electric vehicle application, significant volumes of electrolyte will have to be carried in the battery to assure adequate range, thus reducing the power and energy density of the battery. Certain additives in the electrolyte have been shown to improve the capacity of the battery. One possible additive is silica, which has been shown to prevent unwanted precipitation of zinc oxide. $^{14}$

\subsection{CIRCULATING ELECTROLYIE SYSTEMS}

The circulating electrolyte concept for the zinc-air battery evolved as a means to overcome two basic problems inherent in the static system. Firstly, repeated cycling of the $z$ inc anodes causes dendrites, passivation and shape change, and the deterioration of the integral structure of the electrode. Secondly, zinc reacts with the alkaline electrolyte, spontaneously reacting to liberate $\mathrm{H}_{2}$ and form a metallo-hydroxide complex. This self-discharge side reaction is not only inefficient but could create a safety problem if the hydrogen gas is allowed to build up.

The principles on which the zinc-air battery with the circulating electrolyte operates are:

1. Solid zinc is used as a base and deposited zinc is used as the active material. This facilitates the use of all or most of the plated zinc during discharge. 
2. Electrolyte is circulated continually both during charge and discharge.

3. Reaction products are stored and/or processed external to the battery.

The schematic diagram of the system is shown in Figure 2.2

The anode on which metallic zinc is plated consists of a thin inert conductive substrate and the cathode is a conventional air cathode. At the end of discharge, the inert substrate is essentially depleted of all metallic $z$ inc and when fully charged, the quantity of zinc present is proportional to the designed capacity of the cell.

During discharge, the dissolved $z$ inc forms $z$ incate ions. This material is removed from the battery stack by the circulating electrolyte. The electrolyte containing the zinc is stored external to the systen and is reprocessed in a separate cell where the charging process is the reverse of the above. The dissolved zinc is plated back on the inert substrate in the form of metallic zinc with the evolution of oxygen gas on the surface of an oxygen evolving electrode. During the charging phase a non-dendritic smooth deposit of the zinc has to be obtained. Additives are required and the current density has to be low in order to obtain the uniform plating of zinc on a planar substrate. ${ }^{15}$ GM's experience has been that swelling of these electrodes during operation causes serious problems with rapid mechanical refuelability. This system is capable of achieving a high energy density, however, additional components in the system (e.g., punps, holding tanks) are needed for electrolyte circulation and zinc storage.

Sanyo Electric Company of Japan has pioneered the development of a particular type of circulating electrolyte zinc-air batteries which makes use of forced circulation of air and electrolyte. ${ }^{13}$ A traction battery (123V, 560A-h) has been successfully tested in large vehicles. Also 15V, 560Ah modules are available for stationary applications. Individual cells within these systems are rated at $560 \mathrm{Ah}$ and $1 \mathrm{~V}$, nominal current density is $80 \mathrm{~mA} / \mathrm{cm}^{2}$ with a maximum of $130 \mathrm{ma} / \mathrm{cm}^{2}$. Figure 2.3 shows schematics of the $124 \mathrm{~V}$ battery. Specifications of the battery are shown in Table 2.1.2 


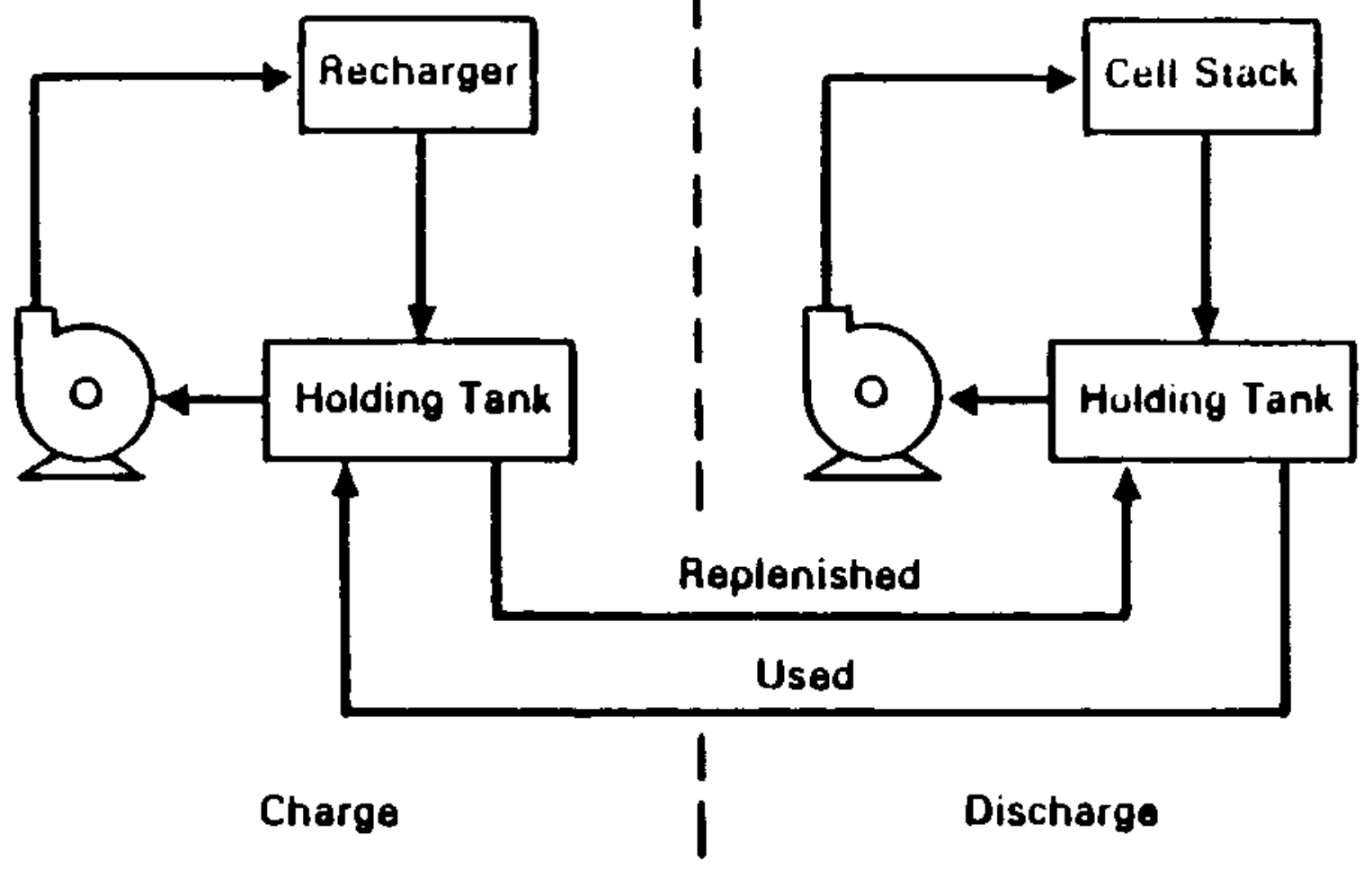

FIGURE 2.2: Schematic of a Circulating Electrolyte Zinc-Air Battery 
TABLE 2.1 ${ }^{(2)}$

Specifications of the SANYO $124 \mathrm{~V}$ Zinc-Air Battery

$\begin{array}{ll}\text { Battery Voltage, } V & 124 \mathrm{~V}(0.2 \mathrm{C}) \\ \text { Capacity Ah } & 540,130 \mathrm{~A}-\max \\ \text { Specific Energy Wh/Kg } & 109 \\ \text { Specific Energy Wh/L } & 100 \\ \text { Weight, } \mathrm{Kg} & 565 \\ \text { Cycle life } & 200-300 \\ \text { Dimensions }(\mathrm{L} \times \mathrm{W} \times \mathrm{H}) \text {, man } & 1550 \times 1050 \times 334\end{array}$

New low-cost processes for making metal-foams out of a wide variety of metals shows great promise in improving the performance of the zinc electrode without detrimental shape changes. ${ }^{12}$ The stationary metal foam acts as a sponge onto which zinc metal is plated during charging and subsequently stripped during the discharge process. A saturated electrolyte solution of $\mathrm{KOH}$ flows through the electrode creating a larger reactive surface than with the solid $z$ inc electrode. A 15 Ah size cell was fabricated containing this modified zinc electrode using nickel positives in place of the air electrode and has demonstrated over 600 cycles without difficulty.

The limited cycle-life of the three electrode zinc-air battery developed by Energy Research Corporation for the U.S. Electronic Command, previously described, is thought to be at least partially attributable to morphological changes in the planar zinc electrode. Serious consideration should be given to applying the recently developed foam technology to a three electrode zincair system. A metallic foam coated with zinc metal potentially provides a high surface area, permitting high current density operation. In addition, this type of electrode has been shown to be relatively insensitive to shape-changes and has the potential for demonstrating long a lifetime. 


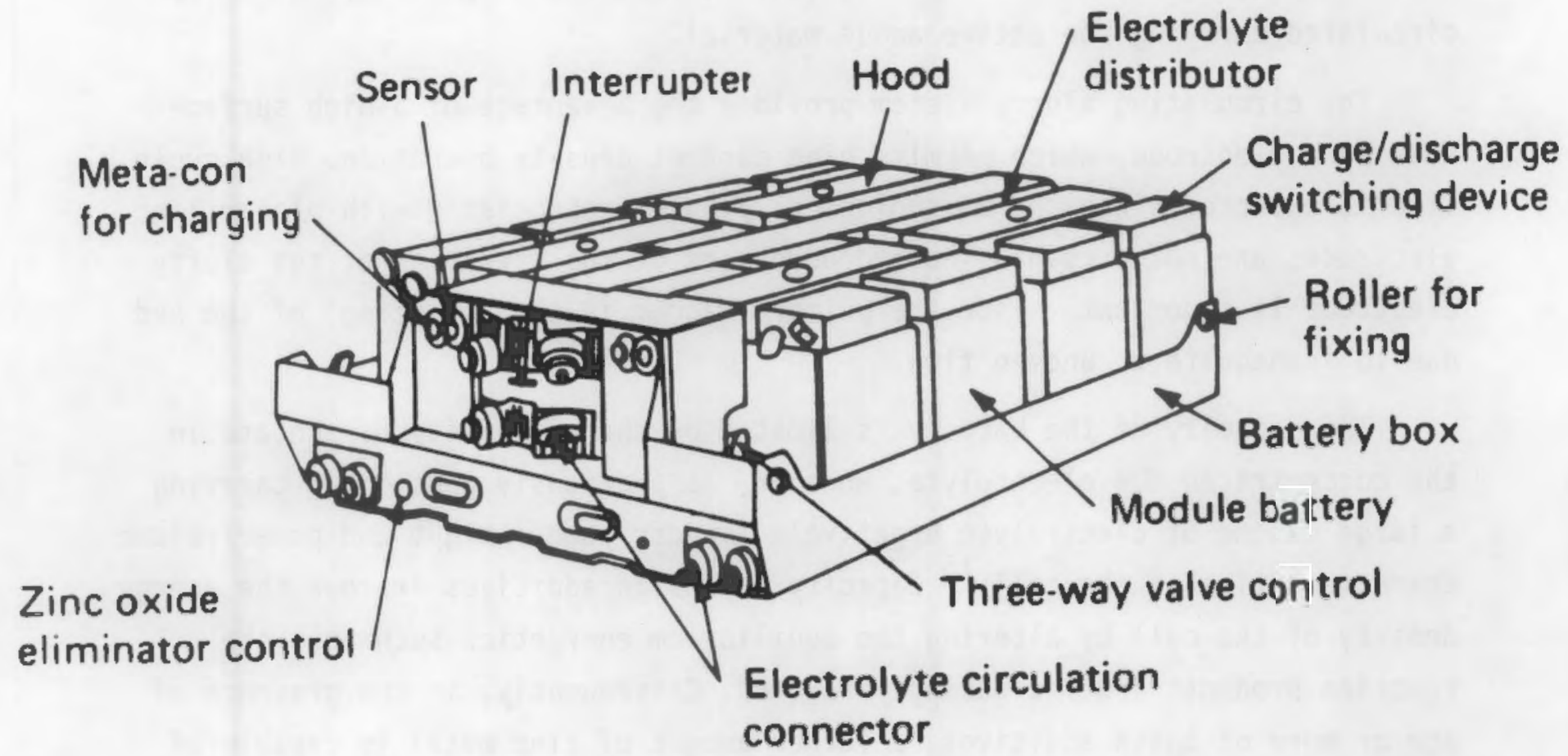

FIGURE 2.3: $124 \mathrm{~V}$ Circulating Electrolyte Zinc-Air Battery 


\subsection{CIRCULATING ZINC-SLURRY SYSTEMS}

A slightly modified version of the circulating electrolyte system is the circulation of a slurry containing both electrolyte and zinc particles in which the zinc particles of the slurry replace the solid zinc anode. The slurry is pumped through either tubular or parallel plate cells and zinc is regenerated external to the cell stack. During charge zinc is deposited in the electrolysis unit and the zinc-KOH slurry is pumped through the cell. During discharge, zinc dissolves to form zincate ions in the electrolyte. The operating scheme is shown in Figure 2.4. The electrolyte is continually circulated carrying the active anode material.

The circulating slurry system provides the advantage of a high surface area zinc electrode, which permits high current density operation. High cycle life is expected since the morphological problems associated with planar zinc electrodes are not present. The hydrodynamics of the operation of the slurry electrode is important, since the primary danger is the "freezing" of the bed due to inadequate or uneven flow.

The capacity of the battery is limited by the solubility of zincate in the concentrated $\mathrm{KOH}$ electrolyte. However, as previously mentioned, carrying a large volume of electrolyte negatively impacts power/weight and power/volume characteristics of the cel1. ${ }^{16}$ Capacity extension additives improve the energy density of the cell by altering the equilibrium energetics such that the reaction products are increasingly favored. Consequently, in the presence of one or more of these additives, a larger amount of zinc metal is capable of being electrochemically oxidized per unit of volume.

An evaluation of the various capacity extending additives has been initiated at P.R.I. under subcontract from L.B.L. ${ }^{17} \mathrm{ZnO}$ can attack the reactive metal anode during discharge causing passivation of the metallic zinc surface. Type $\mathrm{A}$ additives react with $\mathrm{ZnO}$ to produce a suspension of charged micelles containing a hydration sheath, inhibiting the attack on the metal anode. Type $B$ additives increase the cells capacity by catalyzing the formation and stabilizing the thermodynamics of polymeric zincate as shown on page 14 . 


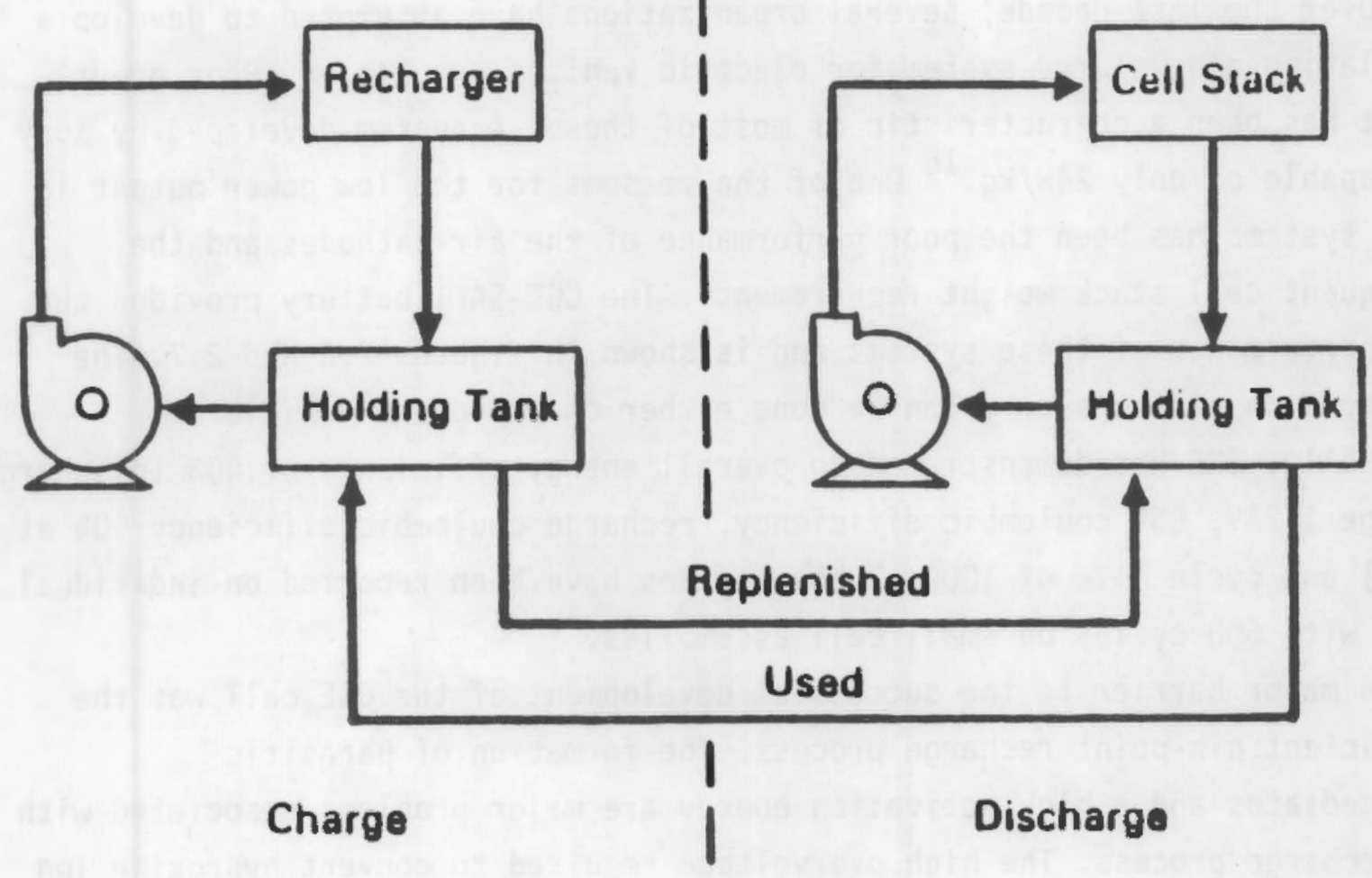

FIGURE 2.4: Schematic of a Circulating Slurry Zinc-Air Battery 


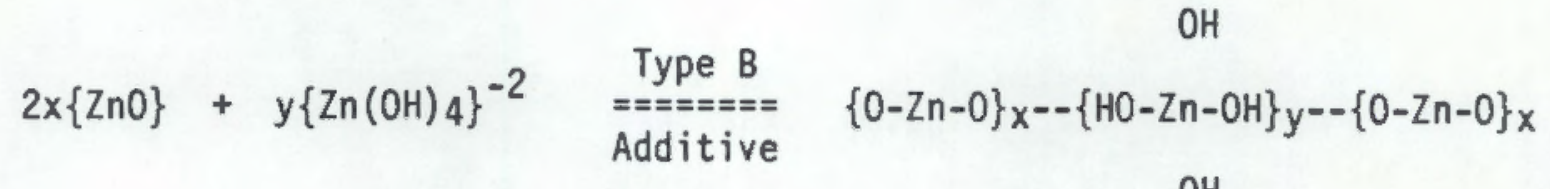

$\mathrm{OH}$

The increased capacity and \% utilization of $Z$ m metal is shown in figure 2.5 . Both silicate, a type $A$ additive and sorbitol, a type $B$ additive, increase the energy density the zinc-air cell as compared to the additive-free system. However, the combination of silicate and Sorbitol yields the optimum energy capacity, indicating the presence of complimentary mechanisms.

Over the last decade, several organizations have attempted to develop a circulating zinc slurry system for electric vehicle propulsion. Poor power output has been a characteristic of most of these. A system developed by Sony was capable of only $24 \mathrm{~W} / \mathrm{kg} .{ }^{18}$ One of the reasons for the low power output in these systems has been the poor performance of the air-cathodes and the consequent cell stack weight requirements. The CGE-SAFT battery provided the best performance of these systems and is shown in figures 2.6 and 2.7. The regeneration of the slurry can be done either on board the vehicle or externally. CGE has demonstrated an overall energy efficiency of $40 \%$ (discharge voltage $1.23 \mathrm{~V}, 85 \%$ coulombic efficiency, recharge coulombic efficiency $90 \%$ at $2.40 \mathrm{~V}$ ) and cycle life of 1000,3 hour cycles have been reported on individual cells with 600 cycles on small cell assemblies. ${ }^{19-21}$

A major barrier to the successful development of the CGE cell was the inefficient pin-point recharge process. The formation of parasitic intermediates and a high activation energy are major problems associated with the recharge process. The high overvoltage required to convert hydroxide ion into molecular oxygen can be avoided by depolarizing the anode with molecular hydrogen gas as shown below. (2)

Reaction

$$
\begin{array}{lll}
2 \mathrm{OH}^{-}-\ldots-- & 1 / 2 \mathrm{O}_{2}+\mathrm{H}_{2} \mathrm{O}+2 \mathrm{e}^{-} & 2.40 \mathrm{~V} \\
2 \mathrm{OH}^{-}+\mathrm{H}_{2}-\cdots--->2 \mathrm{H}_{2} \mathrm{O}+2 \mathrm{e}^{-} & 0.76 \mathrm{~V}
\end{array}
$$

(2) Unpublished results by P. Foller
Cell Voltage 


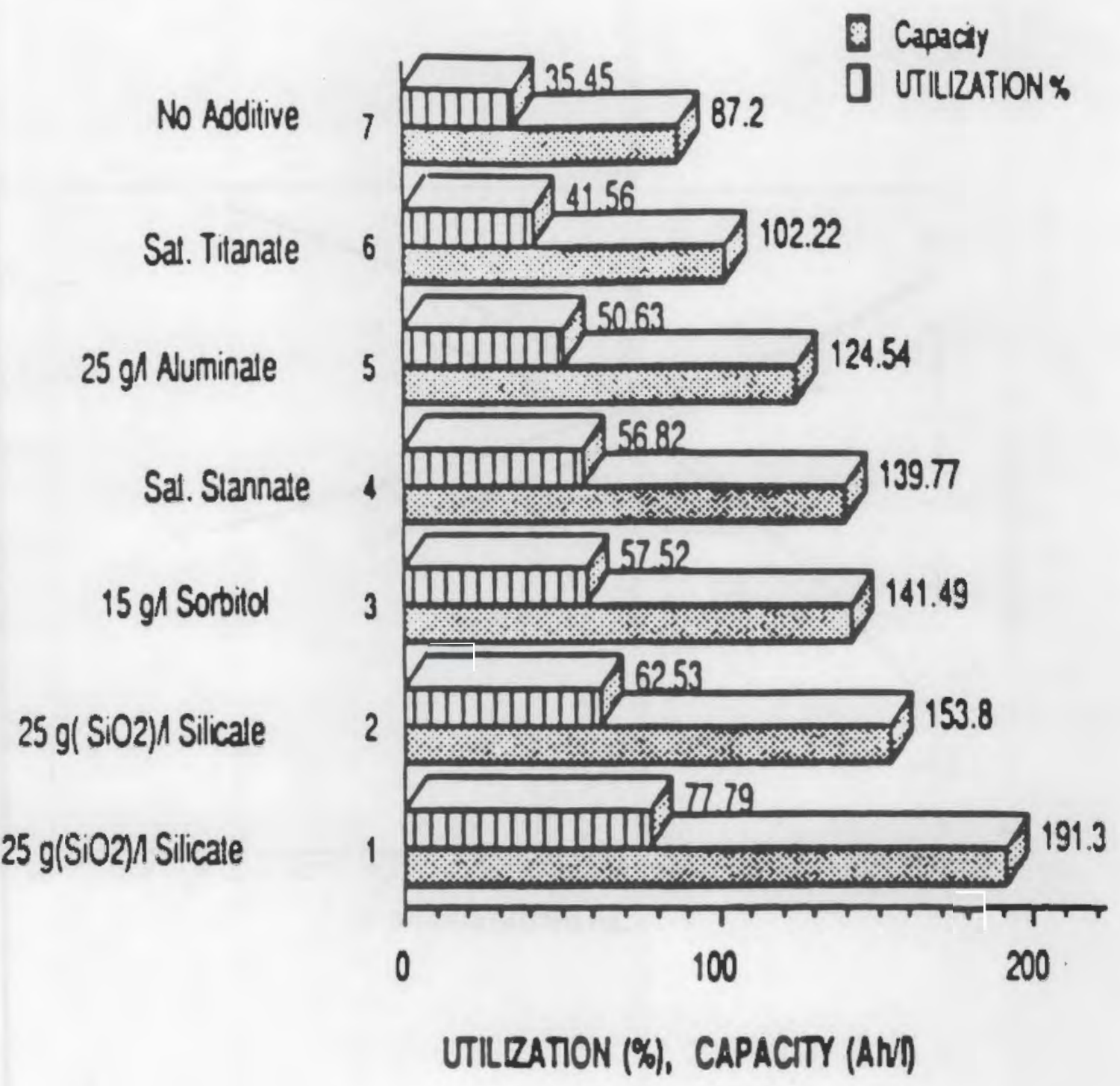

FIGURE 2.5: Zinc Utilization and Capacity Extension of Selected Type A and B Additives in $12 \mathrm{M} \mathrm{KOH} \mathrm{Zn} \mathrm{Powder} \mathrm{Slurry}$ 


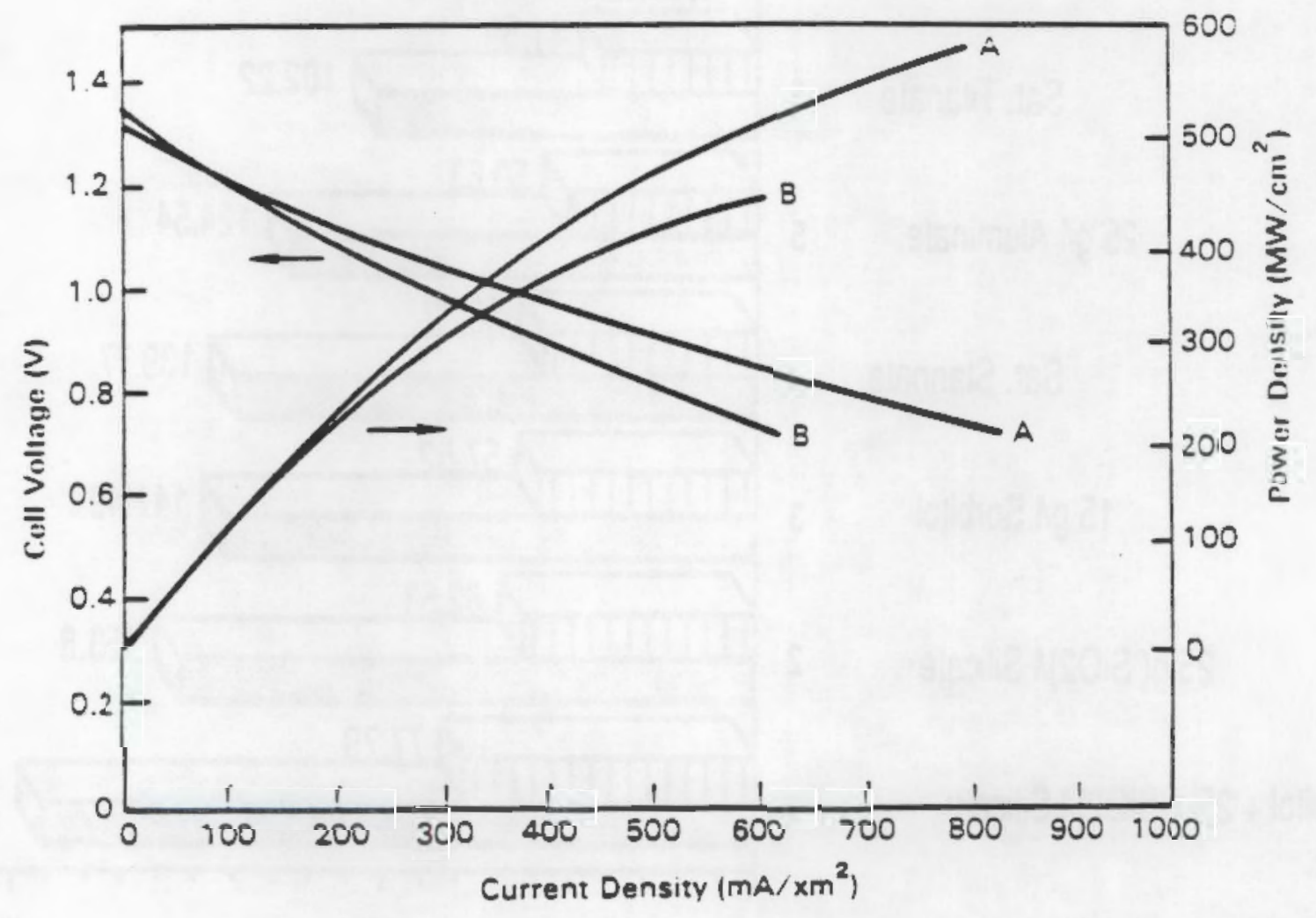

FIGURE 2.6: Discharge Performance of a Zinc-Air Slurry Type Laboratory Cell at CGI 


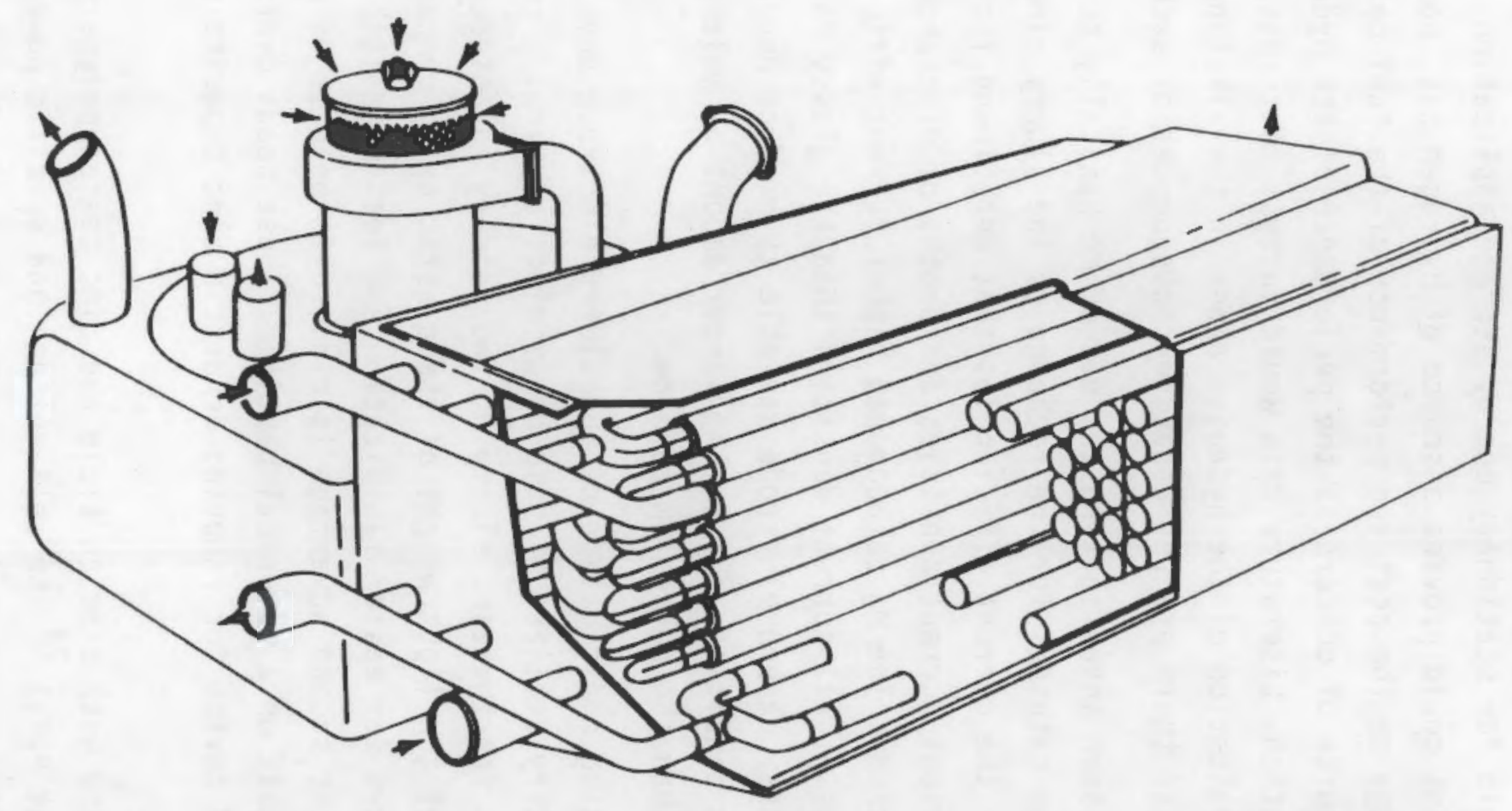

FIGURE 2.7: Overall View of the CGE Circulating Slurry Zinc-Air Battery 
The favorable energy efficiency of this system, coupled with the adequate performance characteristics of hydrogen electrodes in alkaline fuel cells, may make it viable for stationary energy storage application. A coal gasification plant could provide a source of hydrogen gas, however, the impact of this technology on the cost and performance of the fuel cell is not known. An additional source of concern is the performance of the hydrogen anode in the zincate solution. Literature data would suggest that this impact is minimal, however, some evaluation of the hydrogen anode in the alkaline electrolyte is needed to asses if there are any negative consequences of such a operation.

P.R.I. has been investigating the use of mechanically scraped magnesium and glassy carbon cathodes for the recharge of the slurry zinc battery. ${ }^{22}$ Figure 2.8 shows the current efficiencies that were found for the Mg planar electrode at various current densities and depths of discharge after the passage of $300 \mathrm{c} / \mathrm{cm}^{2}$. The $\mathrm{Mg}$ cathode had higher current efficiencies and lower charging voltages at all current densities than the glassy carbon cathode. However, the glassy carbon electrode was able to produce dendritic zinc powders at lower current densities, due to the larger amount of molecular hydrogen gas generated, than the magnesium cathode.

An interesting modification of the slurry electrode developed at Lawrence Berkeley Laboratory utilizes plastic beads electrolytically coated with zinc as a replacement for the zinc slurry. ${ }^{23}$ Two primary advantages are foreseen. The first is that the light weight of the plastic beads compared to dendritic zinc powder allows for easier fluidization and less parasitic power for pumping of the slurry. The second advantage is claimed to be ease of deposition of a smooth zinc deposit on a spherical particle. These beads overcome the need for a mechanical device for removing dendritic zinc deposits during the charging process.

Slurries made with zinc particle and zinc coated polymeric beads (SORAPEC) were evaluated at P.R.I. ${ }^{24}$ The cell voltage and specific power as a function of current density are shown in figures 2.9 and 2.10. Very little difference was observed in the discharge performance of these systems using either air or pure molecular oxygen, especially at high current densities. This represents great progress in air electrode technology achieved through the Department of 


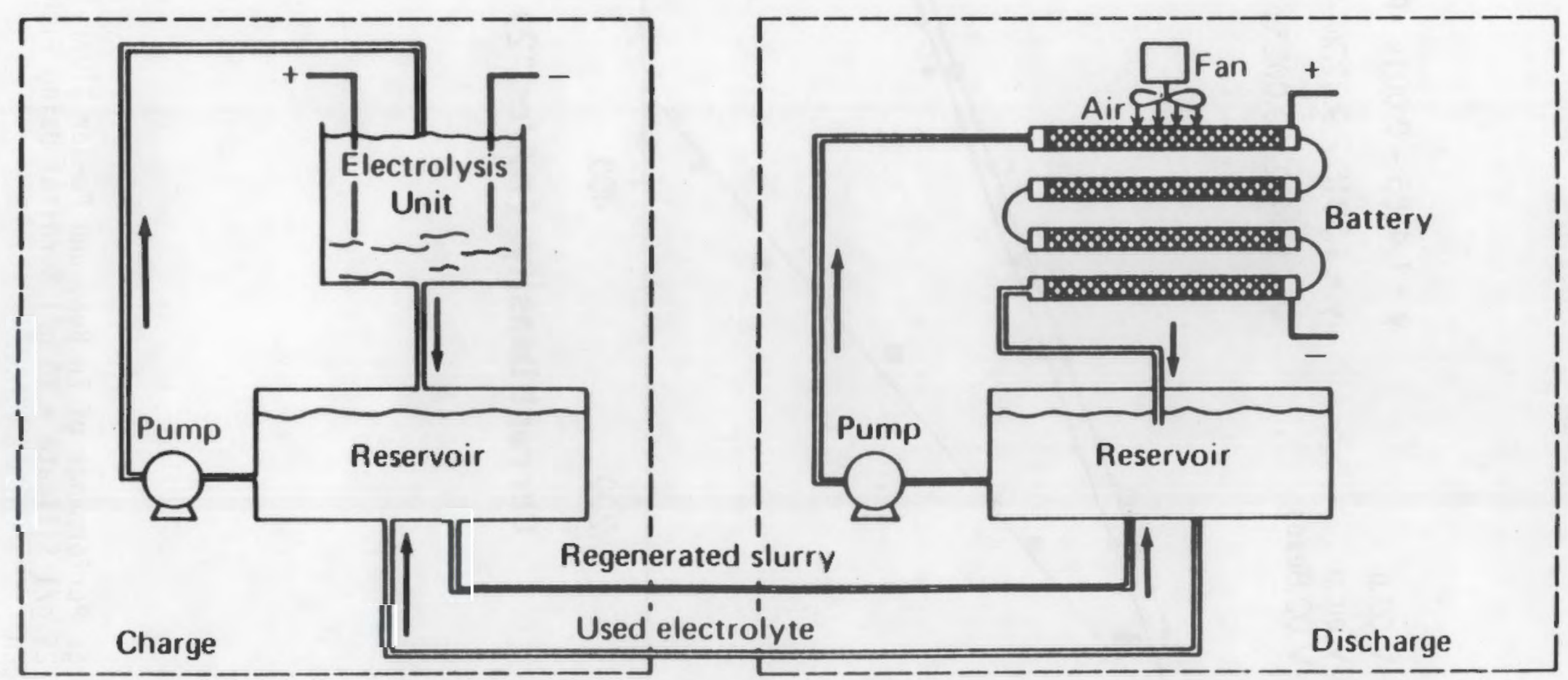




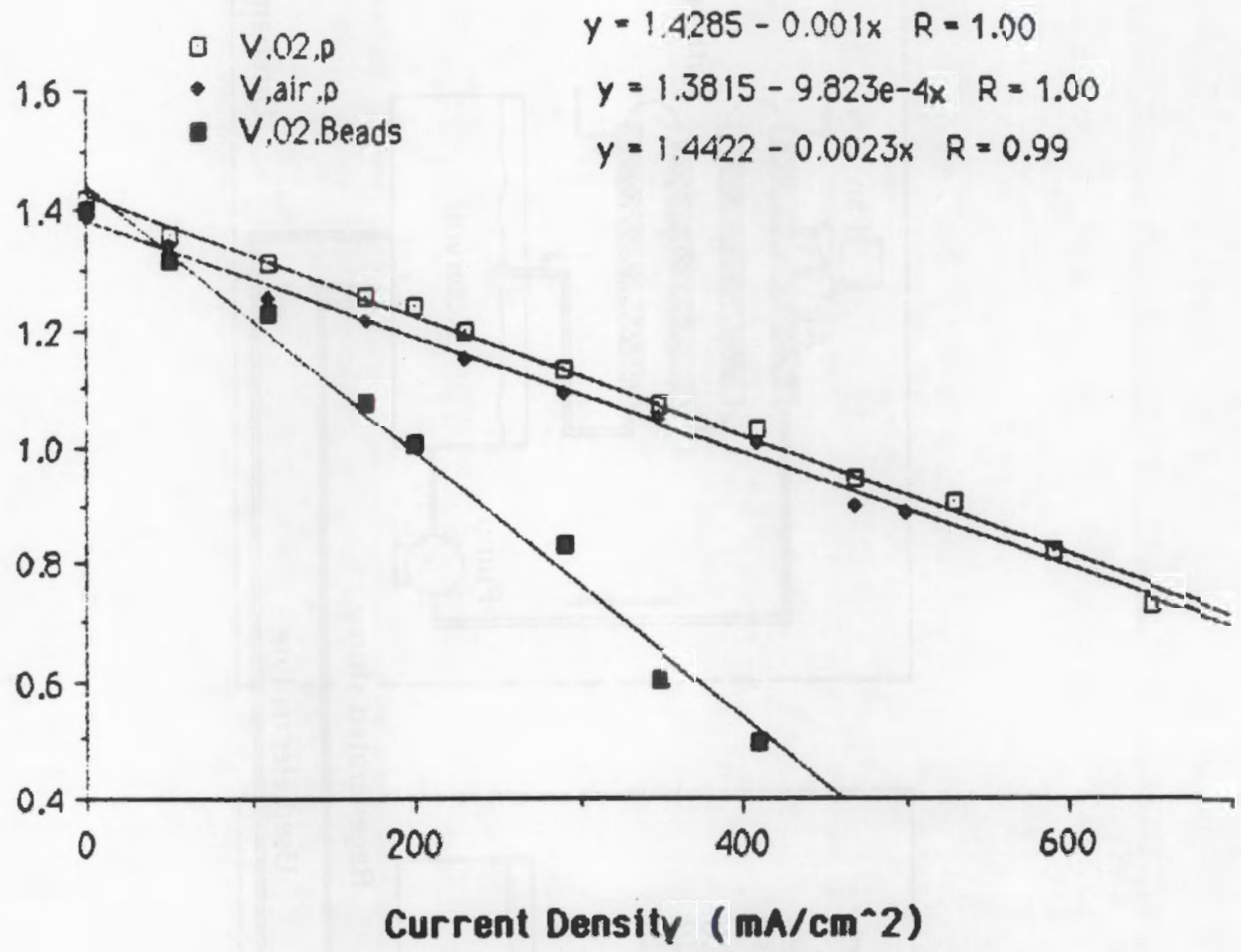

FIGURE 2.9: Discharge Performance of $\mathrm{Zn}$ Bead and Powder Slurry in 12M $\mathrm{KOH}+25 \mathrm{~g} / 1$ Silicate $+15 \mathrm{~g} / 1$ Sorbital Using Either Air or Oxygen 


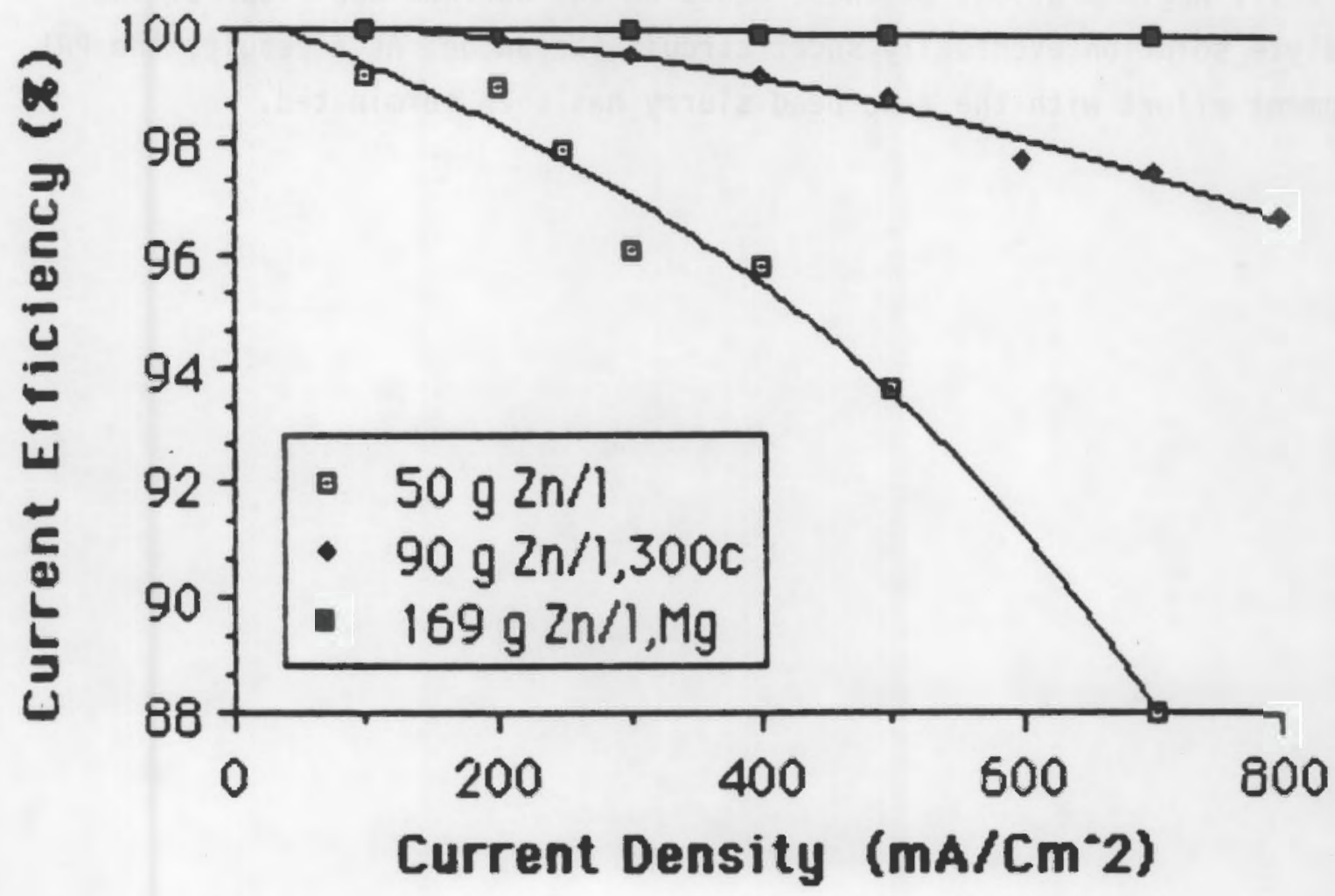

FIGURE 2.10: Current Efficiency vs Current Density Curves for the Electrodeposition of Metallic Zinc on a Stationary, Planar Mg Electrode 
Energy's aluminum/air program. A $30 \%$ reduction in the discharge performance of the SORAPEC zinc beads was observed in comparison to the slurry zinc system. No significant improvement in the discharge performance was detected by varying the concentration of plastic zinc beads in the slurry. It is believed that less collisions take place in the bead slurries, resulting in a diminished time averaged effective area for the zinc anode. In addition, recharge of the zinc beads using a fluidized bed cell was not successful due to fluidation problems. Non-uniform plating of the metallic zinc results in some beads floating on the surface of the electrolyte and some beads sinking to the bottom of the cell. Agglomerations of these beads on the surface and floor of the electrolyte solution eventually short circuit the anode. As a result, the PRI development effort with the zinc bead slurry has been terminated. 


\subsection{ALUMINUM-AIR BATTERY}

\subsection{GENERAL CONSIDERATIONS}

Aluminum has attracted attention as a potential battery anode because of its high ampere-hour capacity (2980 Ah per $\mathrm{Kg}$ of $\mathrm{Al}$ ). However, aluminum cannot be used in a conventional secondary battery configuration with aqueous electrolytes since it is impossible to electrodeposit aluminum from an aqueous solution. Interest in aluminum-air primary batteries which could be mechanically recharged began to develop in the $1960 \mathrm{~s}^{25}$ Two types of mechanically rechargeable aluminum-air cells have been developed since the 1960s, batteries containing neutral (saline) and strongly alkaline electrolytes. The overall reaction at the electrodes are shown below.

NEUTRAL MEDIA

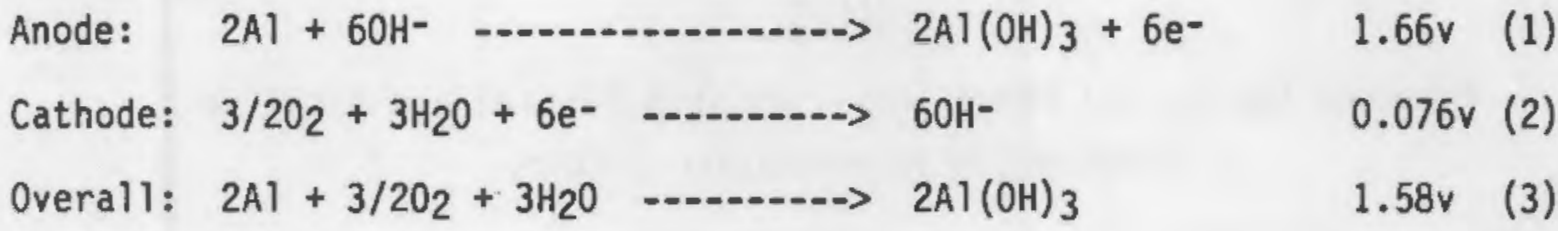

ALKALINE MEDIA

Anode: $\quad 2 \mathrm{Al}+80 \mathrm{H}^{-}-(4)$

Overall: $2 \mathrm{Al}+2 \mathrm{OH}^{-}+3 / 2 \mathrm{O}_{2}+3 \mathrm{H}_{2} \mathrm{O} \quad \cdots--->2 \mathrm{Al}\left(\mathrm{OH}_{4} 4^{-} \quad 2.75 \mathrm{~V}(5)\right.$

The expected voltage of these batteries is lower in neutral solutions than in alkaline media. The reaction product in neutral solutions is a gelatinous mass of $\mathrm{Al}(\mathrm{OH})_{3}$ which interferes with the operation of the electrochem ical cell. In strongly alkaline media, the electrochemical reaction products are soluble, readily entering the super-saturated state. The precipitation reaction from the super saturated state is given below:

$$
\mathrm{Na}+\mathrm{Al}(\mathrm{OH})_{4}-\left(-\cdots+-.-\mathrm{Na}^{+} \mathrm{OH}-+\mathrm{Al}(\mathrm{OH})_{3}\right.
$$


Although the overall reaction indicated above (eqn. 5) shows a consumption of $\mathrm{NaOH}$ and $\mathrm{H}_{2} \mathrm{O}$, it should be remembered that the precipitation reaction ${ }^{6}$ produces the equivalent amount of $\mathrm{NaOH}$. The initiation of precipitation can be controlled by adding seed crystals of hydragillite to the super saturated solution. This controlled precipitation can be made to occur in a separate vessel outside the electrochemical cell.

The difference between the neutral and alkaline electrolyte is basically 1) terminal voltage and 2) reaction product precipitation. The precipitation problem with the neutral electrolyte increases the complexity of the aluminum/air battery system design. This, combined with the lower cell voltage, makes the neutral electrolyte system less attractive for applications such as electric vehicles. The energy and power densities which are considered to be attainable by the neutral and alkaline electrolyte system are shown in Table 3.1.

TABLE 3.1

Expected Energy and Power Densities from Neutral and Alkaline Electrolyte Aluminum/Air Battery

Electrolyte
Power Density

$\mathrm{W} / \mathrm{Kg}$
Energy Density

Wh/ $\mathrm{Kg}$

Neutral (Saline)

30

220

$4 \mathrm{M} \mathrm{NaOH}$

150

400

The power density differences are fairly easily explained by current density limitations. The neutral electrolyte battery can operate at current densities of approximately $50 \mathrm{~mA} / \mathrm{cm}^{2}$, whereas in the strongly alkaline system current densities of $600 \mathrm{~mA} / \mathrm{cm}^{2}$ are achievable with a cell voltage of approximately one volt. The energy density difference arise because the alkaline system precipitates $\mathrm{Al}(\mathrm{OH})_{3}$ as a crystalline hydragillite, while in neutral solutions a tri-hydrate gel is formed containing large amounts of free water associated 
with it. Typically the gel cannot be filtered and is kept in suspension until the whole reservoir can be flushed out. Thus, the capacity level of the alkaline electrolyte is unobtainable in a neutral solution until a procedure for the rapid precipitation of the tri-hydrate gel is developed.

The limitations in power density of the neutral electrolyte system restricts its application to that of a range extender in a electric vehicle. Thus, this assessment is focused on the alkaline electrolyte aluminum-air battery system.

\subsection{ALKALINE ELECTROLYTE ALUMINUM-AIR SYSTEM}

The schematic of an alkaline aluminum/air battery system is shown in Figure 3.1. The electrochemical cell and the electrolyte management system are two key components of this system. The electrochemical cell operates around 600. $80^{\circ} \mathrm{C}$ with forced circulation of electrolyte and air, with the air supplied being scrubbed to reduce the carbon dioxide content. Hydrogen is generated by a parasitic corrosion reaction between aluminum and water and safe disposal of this gas is necessary. Heat rejection is achieved by a combination of evaporative cooling and a radiator. The crystallizer provides the electrolyte concentration control through the precipitation of $\mathrm{Al}(\mathrm{OH})_{3}$ from a super saturated solution of caustic aluminate. Finally, tanks are provided for the electrolyte, water and hydrate storage.

\subsubsection{The Battery}

The useful energy obtained from a cell depends upon several factors including (a) the thermodynamics of the chemical reaction, (b) the kinetics of the electrode processes and (c) the ohmic resistance of the electrolyte. It follows then that the electrochemistry of the aluminum anode and of the air cathode are critical in terms of defining energy efficiency and operating life.

In aqueous solutions the overpotentials for the anodic dissolution of aluminum are high due to the presence of a strongly-adhering oxide film at the metal surface. Appreciable rates of dissolution are obtained in solutions containing aggressive anions, e.g., chloride ions, or in strongly alkaline solutions. ${ }^{26}$ Activating elements such as gallium, indium or tin have been 


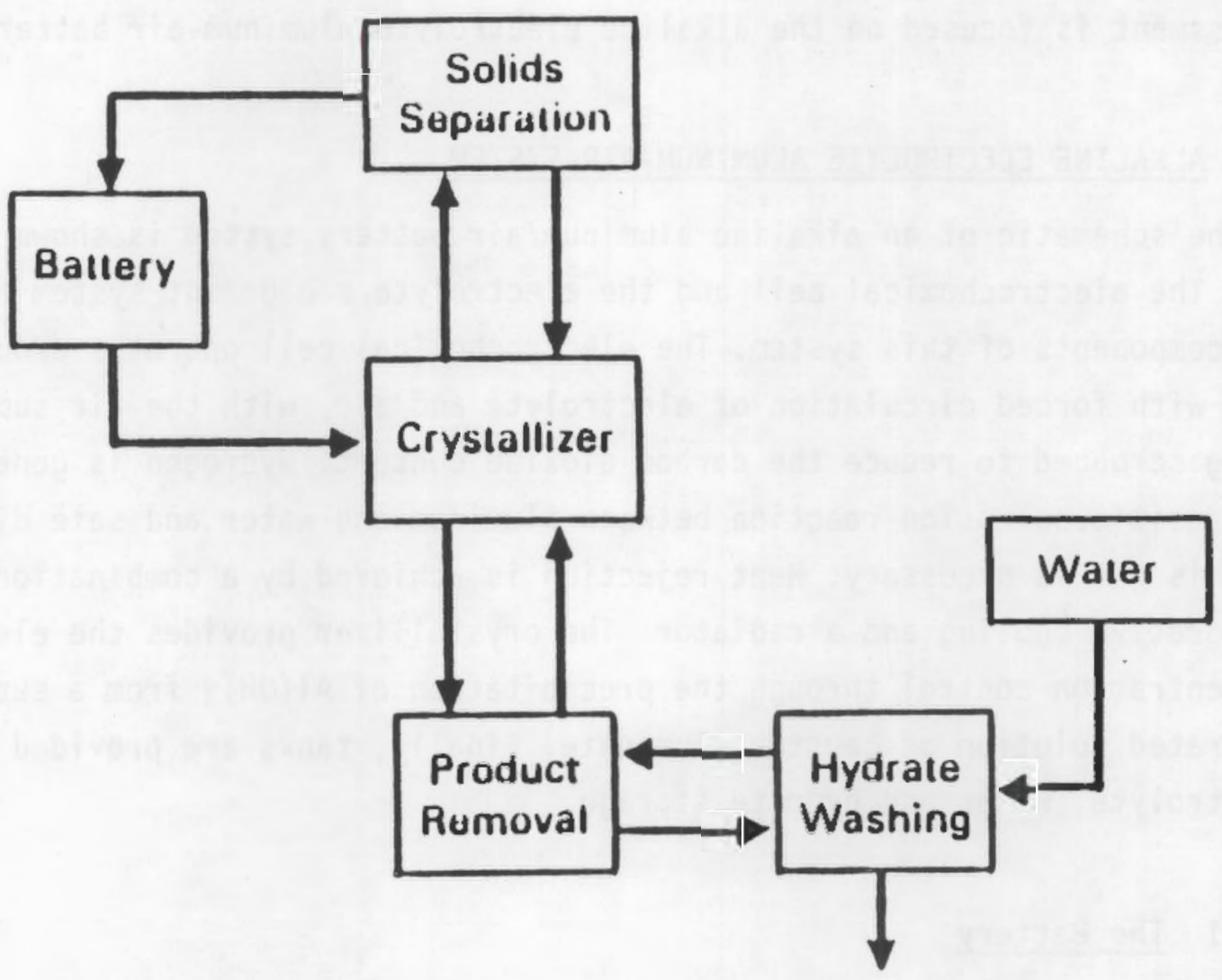

FIGURE 3.1: Schematic of an Alkaline Aluminum-Air Battery System 
alloyed with the aluminum to lower the overpotential for dissolution, thereby increasing the power and energy output for the aluminum-air ce11. 27 It has also been shown that the behavior of these alloys is sensitive to the thermal and mechanical treatments involved in fabrication. This suggests that the microstructure of the metal or allow may control the dissolution process.

In addition to the high voltage efficiency, a high current efficiency is also required. The rate of corrosion of aluminum in alkaline electrolytes is substantial, e.9., 99.99\% aluminum exhibits an open circuit corrosion current density of $280-300 \mathrm{~mA} / \mathrm{cm}^{2}$, resulting in a low current efficiency. Addition of elements that exhibit a high overpotential towards hydrogen evolution, together with careful control of the thermal cycles in the fabrication, has effectively reduced corrosion rates to approximately $25-30 \mathrm{~mA} / \mathrm{cm}^{2}$. The addition of an inhibitor to the electrolyte has also been explored, the additive effectively suppressing the hydrogen evolution reaction and therefore the parasitic corrosion reaction. For example, limited success has been obtained by adding sodium stannate to the electrolyte and this approach probably warrants further study.

The air electrode is also a critical component of the battery, being required to operate over a period of at least two years under demanding drive cycles. The required performance of the air cathode has been expressed in terms of the overpotential (volts vs reversible hydrogen electrode):

$$
V_{\text {cathode }}=0.876-0.4 i
$$

where $i$ is the operating current density expressed in amps/ $\mathrm{cm}^{2}$. Progress has been made in the development of the air cathodes such that they are able to essentially satisfy this target performance.

Early designs of aluminum-air cells followed the familiar filter press configuration with two metal plates separated by a removable air cathode module. ${ }^{28}$ Refuelable cells were fabricated using a fixed anode and a moving cathode-separator module, with electrical contact to the anode being made at the metal-electrolyte interface. ${ }^{29}$ These early cells did not allow total dissolution of the anode plate, a limitation that was overcome by the wedgeshaped anode developed by Despic et at. ${ }^{30}$ Combined with solution side current collection a cell using a wedge anode offered the advantages of continuous 
fuel feed, complete utilization of aluminum and rapid refuelability. A cell of this type is shown as Figure 3.2 .

\subsubsection{The Electrolyte Management System}

As the battery operates, aluminum is dissolved from the anode gradually producing a super saturated solution of aluminate in the electrolyte. The electrolyte management system crystallizes the aluminate out of this supersaturated solution as hydragillite and returns the rejuvenated electrolyte to the battery. The controlled removal of hydragillite from the super-saturated electrolyte is needed to avoid the precipitation of gelatinous aluminum hydroxide which severely affects the batteries' performance. Furthermore the conductivity of the electrolyte decreases markedly as the aluminate concentration increases.

The key components of the electrolyte management system are shown in Figure 3.1. The crystallizer contains the seed hydragillite particles. As the super saturated electrolyte encounters the seed particles in the crystallizer, precipitation of the $\mathrm{Al}(\mathrm{OH})_{3}$ is initiated. A certain residence time is required for the newly formed crystals to grow to an acceptable size. These particles are then filtered, washed and periodically removed from the system. The rejuvenated electrolyte from the crystallizer still contains some fine particles which are removed at the solid separation stage. The electrolyte is then returned to the battery.

\subsection{PRESENT DEVELOPMENT STATUS}

The primary effort to develop an alkaline aluminum-air battery for electric vehicle application is sponsored by the Department of Energy and cost-shared with Eltech Research Corporation as the prime subcontractor. This program is a continuation of the research and development conducted during the last seven years by Eltech and the Department of Energy. The main objective of the program is to install an aluminum-air battery in an electric vehicle and the time frame to achieve this objective is six years. The technical program is managed by Sandia National Laboratories and involves programs at Eltech (battery optimization, heat exchanger design, $\mathrm{CO}_{2}$ scrubber design and 


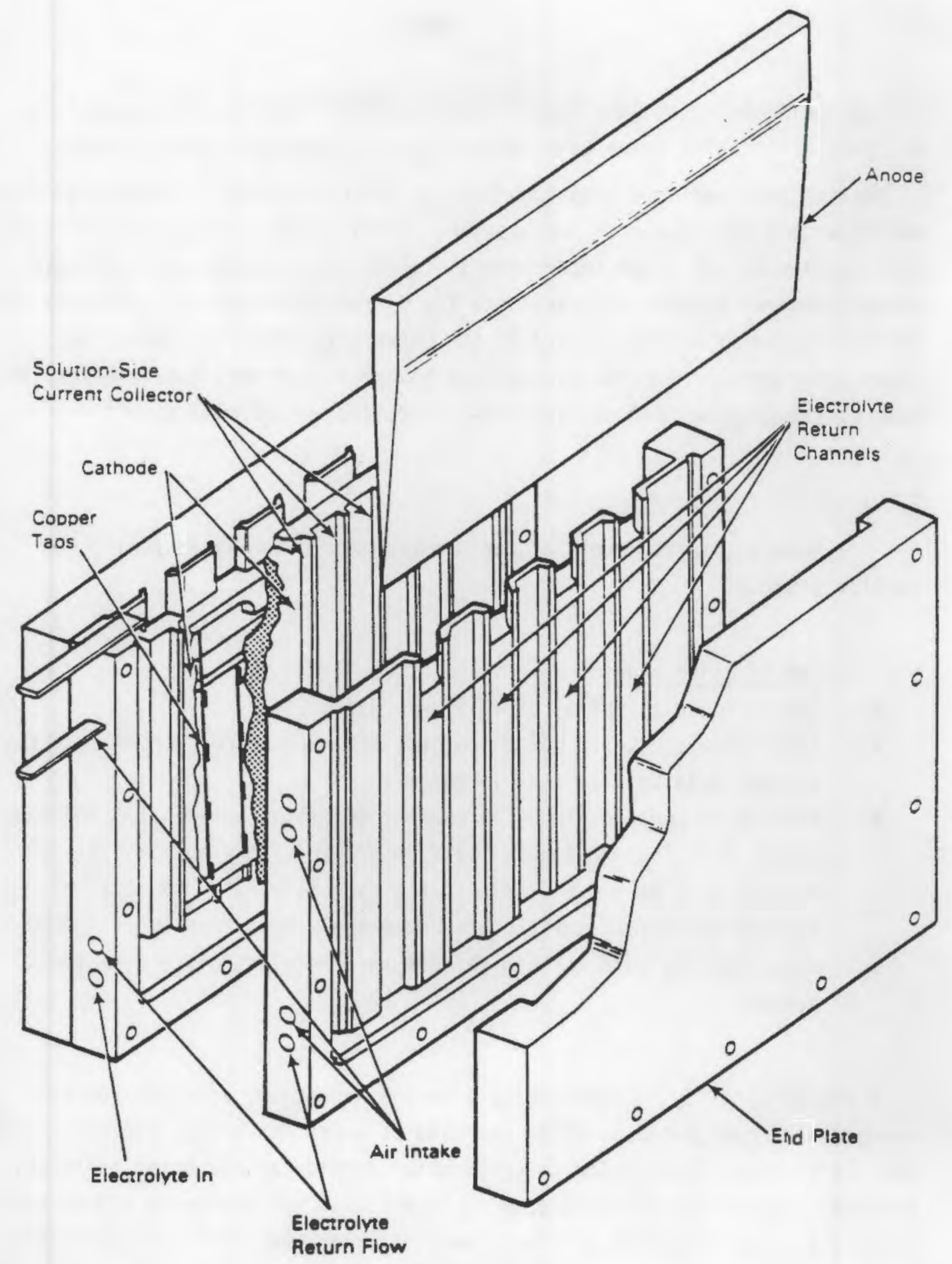

FIGURE 3.2: The Alkaline Aluminum-Air Cell 
hydrogen disposal), at Case Western Reserve University (modelling) and at Helipump Corporation (separation technology for electrolyte management).

Earlier programs were also sponsored by the Department of Energy and costshared with Eltech Research Corporation. Within these programs research was also carried out at Alcan International (electrolyte management), at Case Western Reserve University (catalysts for $0_{2}$ reduction and air cathodes), at SRI (corrosion of aluminum), and at the University of Akron (modelling). These programs were managed by Lawrence Livermore National Laboratories, where much of the original R\&D on aluminum-air systems was carried out. ${ }^{31}$

\subsubsection{Battery Components}

Several target levels of performance were established during the earlier programs:

\section{The Aluminum Anode}

- Open circuit potential of $-1.81 \mathrm{v}$ vs $\mathrm{Hg} / \mathrm{HgO}$.

- open circuit rate of corrosion less than $0.1 \mathrm{mg} / \mathrm{cm}^{2} / \mathrm{min}$ or a corrosion current density less than $10 \mathrm{~mA} / \mathrm{cm}^{2}$.

- ability to operate stably at current densities between 100 and 600 $\mathrm{mA} / \mathrm{cm}^{2}$ with the anode potentials described by the equation $\mathrm{V}_{\mathrm{a}}$ (vs. $\mathrm{Hg} / \mathrm{HgO})=-1.81+0.5 i$ where is the current density in amps $/ \mathrm{cm}^{2}$. Thus at $600 \mathrm{~mA} / \mathrm{cm}^{2}$ the expected potential is -1.5 volts $\mathrm{vs} \mathrm{Hg} / \mathrm{HgO}$. - compatibility with the air cathode and the electrolyte management system.

A specialty alloy, containing gallium and magnesium, manufactured by Reynolds and designated as RX808 was used as a benchmark when the R\&O programs were initiated. Eltech Research Corporation adopted an Edisonian approach, evaluating a variety of alloys, using both sodium and potassium hydroxide as the electrolyte. Families of alloys were investigated within the programs based upon commercial availability, literature review of the effects of certain metals, and special anodes prepared by Alcan International and Reynolds Aluminum Company. ${ }^{33}$ Common alloying elements such as calcium, bismuth, gallium, indium, 
magnesium, manganese and tin were used to prepare binary and ternary alloys. Other alloys containing combinations of phosphorous, lead, antimony, thallium or zinc were also evaluated. No distinct trends relating the electrochemistry to alloy composition were established and it is evident that the metallurgical properties of the alloys and thermal cycles experienced during fabrication are important.

The best results were obtained with alloys containing low levels of gallium, indium, manganese and/or magnesium. Figures 3.3 and 3.4 show the open circuit behavior of several alloys together with pure ( $99.99 \%)$ and ultra-pure ( $99.999 \%)$ aluminum. The alloys designated 353, 355 and 357 are proprietary and BDW is an alloy developed by Alcan International, containing indium, manganese and magnesium.

It is apparent that neither pure nor ultrapure aluminum exhibit acceptable rates of corrosion, whereas the alloys approach the target level of $10 \mathrm{~mA} / \mathrm{cm}^{2}$. The polarization behavior for the BDW alloy is shown as Figure 3.5 and the overall performance of this alloy essentially met the specific energy density and specific power density targets established for the program, i.e., 4.3 $\mathrm{kWh} / \mathrm{kg} \mathrm{Al}$ and $0.6 \mathrm{~W} / \mathrm{cm}^{2}$ respectively.

A more fundamental approach to the development of an aluminum anode was undertaken by Macdonald at SRI, complementing the programs at Eltech and Alcan. Macdonald explored the electrochemistry of aluminum and various alloys using a steady-state potentiostatic technique and wide-bank a.c. impedance spectroscopy. This approach let to:

(a) a better understanding of the mechanisms of alloy activation and passivation, and

(b) delineation of the partial anodic (metal dissolution) and cathodic (hydrogen evolution) currents to allow examination of the effects of the alloying elements upon the separate reactions.

Several of the promising alloy compositions were used to fabricate larger electrodes, e.g., active area $300-400 \mathrm{~cm}^{2}$. These electrodes were operated in 


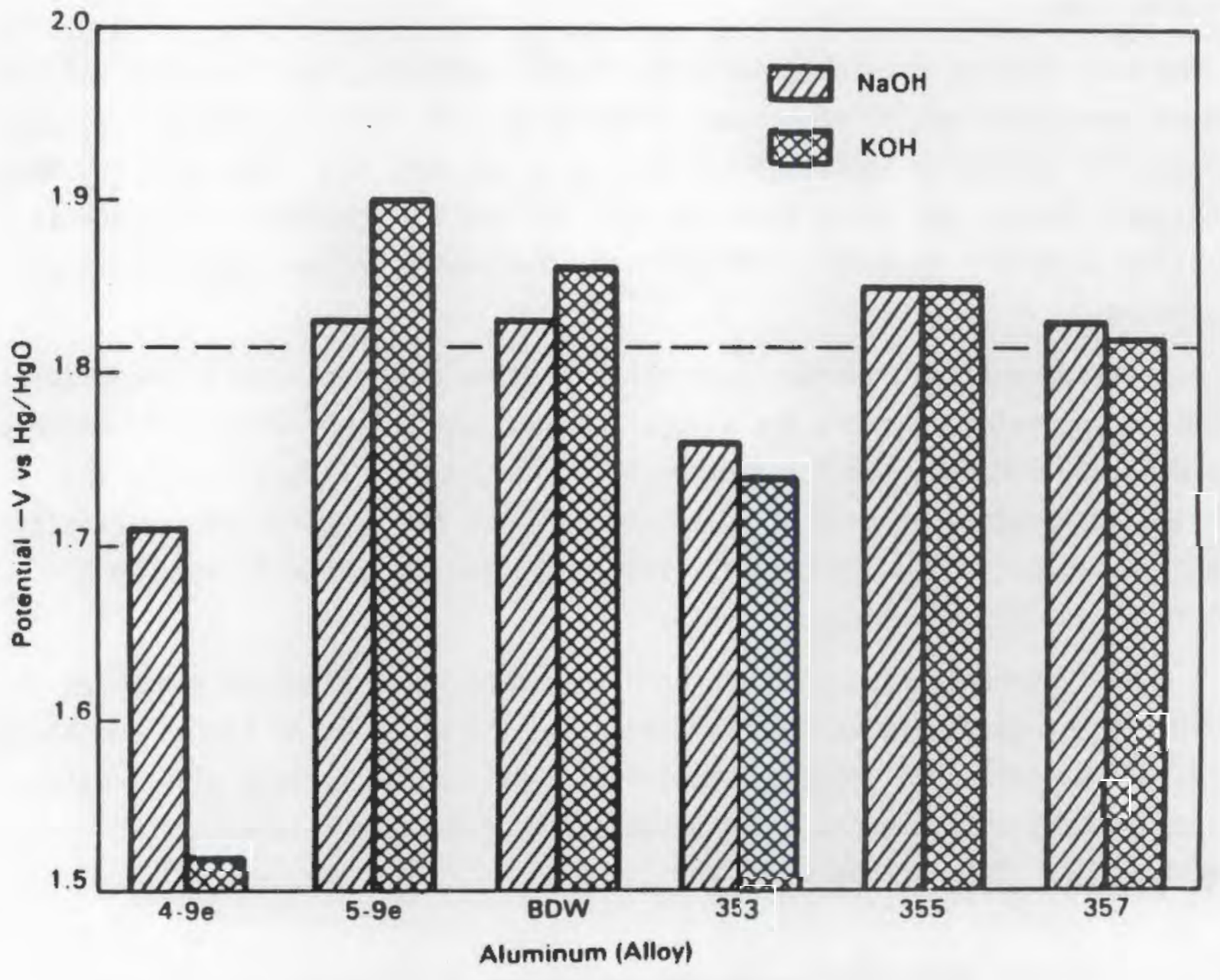

FIGURE 3.3: Open Circuit Potential of Aluminum and Proprietary Aluminum Alloys in $\mathrm{NaOH}$ and $\mathrm{KOH}$ 


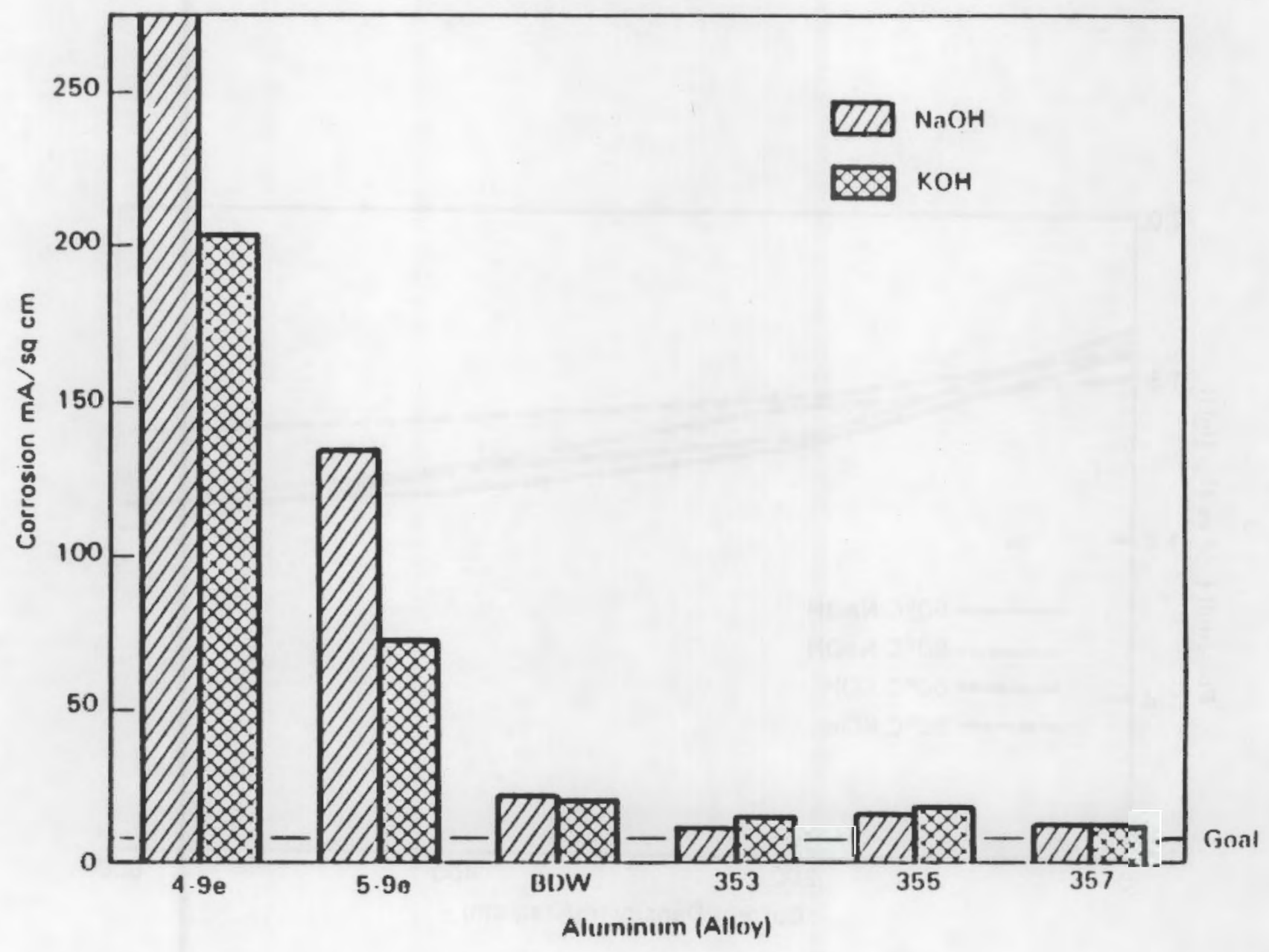

FIGURE 3.4: Corrosion Rates of Auminum and Proprietary Aluminum Alloys in $\mathrm{NaOH}$ and $\mathrm{KOH}$ 


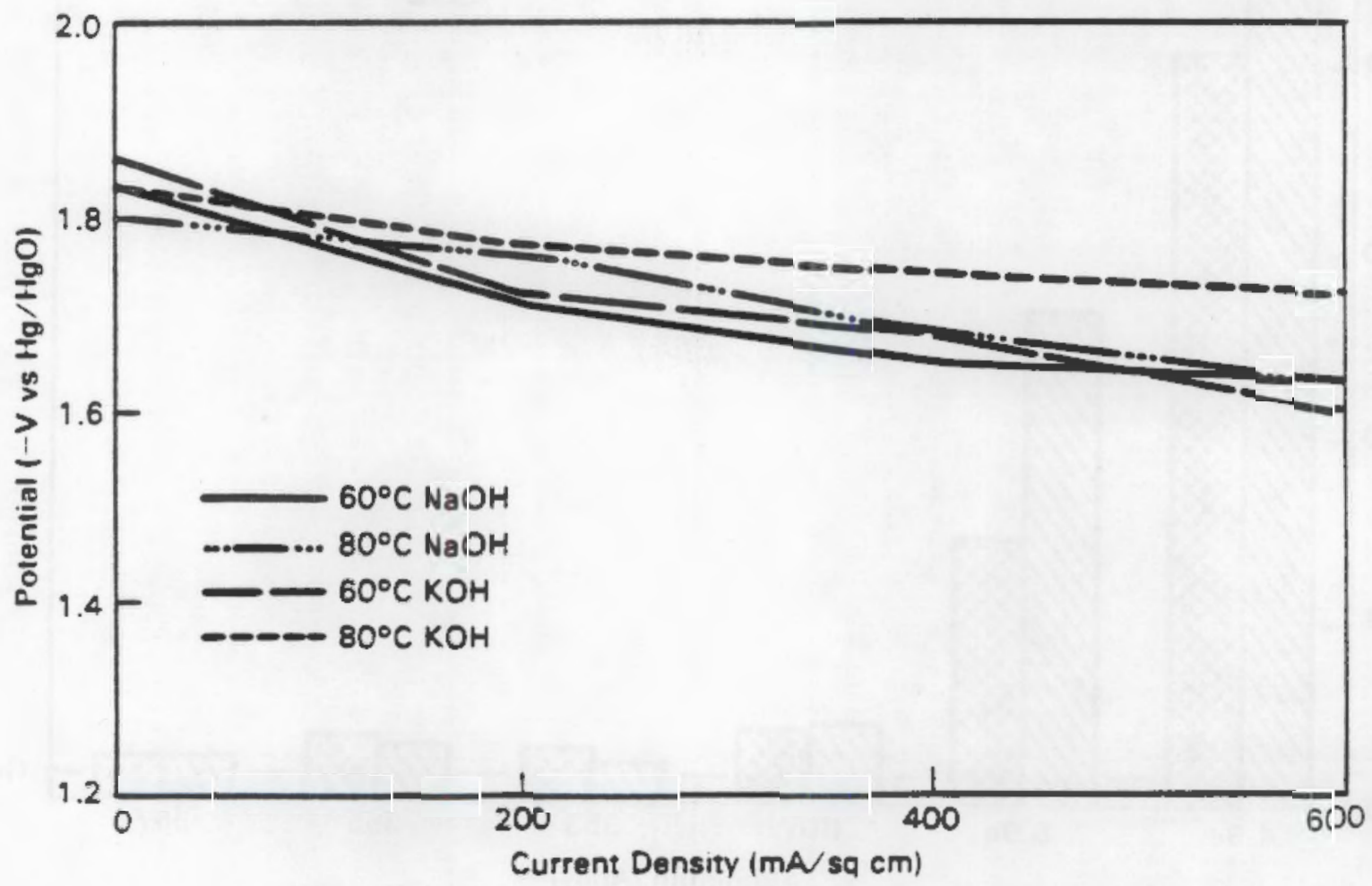

FIGURE 3.5: Current Potential Curve of the Proprietary Alloy $\mathrm{BDW}$ in $\mathrm{NaOH}$ and $\mathrm{KOH}$ 
a battery stack and it was evident that scale-up had modified the electrochemical behavior. In particular the BDW allow did not show the expected performance and analyses of the electrodes indicated some differences in the microstructure of the alloy.

The compatibility of these alloys with the performance of the air cathode and electrolyte management systems have not been fully explored. All four of the alloys are considered to be proprietary by the developers and no data has yet been published which shows the effect of the alloying agents on either the air cathode performance or the electrolyte management system. ELTECH Systems Corporation has conducted generic tests with In, Ga and $\mathrm{Sn}$, as potential alloying elements, in the electrolyte and has found no significant effect on air cathode performance or life. However, preliminary indications from ALCAN suggests that the alloying agents in BDW negatively impact the electrolyte management system by hindering the crystallization process. A clear understanding of the impact of alloying agent on the air cathode and electrolyte management system is definitely a key area for the successful development of the aluminum air battery.

Not much emphasis has been placed so far on the cost of these alloys. Alloys such as BDW are presently prepared with ultrapure aluminum ( $99.999 \%)$ as a starting material. Commercial grade aluminum contains approximately $0.01 \%$ iron impurity which dramatically increases the corrosion rate. Ultrapure aluminum on the other hand has an iron content of only $0.009 \%$ to $0.006 \%$. The cost of producing ultrapure aluminum is quite high, making the cost of the alloys expensive as well. Attempts must be made to produce aluminum alloys from commercial grade aluminum which show acceptable performance in the battery. During the early phases of the program Reynolds attempted to develop an aluminum alloy containing manganese. It is believed that manganese can deactivate the iron impurity by forming an intermetallic complex, greatly reducing corrosion and its concomitant hydrogen evolution. The results of that approach were not fully developed when the contract ended. However, similar approaches must be explored to develop a cost-effective aluminum alloy for the battery. 


\section{The Air Cathode}

The programs funded by the Department of Energy have been coordinated by Eltech Research Corporation and have involved research efforts (1) at Case Western Reserve University (CWRU) for the identification and evaluation of catalysts for the electroreduction of oxygen, and (2) at Electromedia Corporation for the development and fabrication of electrode structures using catalysts identified at CWRU.

The development of an air cathode for use in batteries for an electric vehicle required that the electrodes be evaluated in an environment similar to actual operating conditions. Thus the experimental cathodes have largely been evaluated using a drive cycle, as shown in figure 3.6, representing the idling $\left(100 \mathrm{~mA} / \mathrm{cm}^{2}\right)$, cruising $\left(200 \mathrm{~mA} / \mathrm{cm}^{2}\right)$ and accelerating $\left(600 \mathrm{~mA} / \mathrm{cm}^{2}\right)$ conditions experienced in a vehicle. The standby period is particularly demanding since at the potentials realized, and in the highly alkaline environment, catalysts dissolution and substrate corrosion are substantially enhanced.

A two layer electrode was developed specifically for the aluminum-air battery. Electrical contact is made on the air side of the electrode, so that the hydrophobic layer or gas supply layer must be conductive. It is therefore a blend of a carbon black and a fluoropolymer binder. The active layer (electrolyte side) may use either an activated carbon or a carbon black as the substrate for the catalyst, again with a fluoropolymer binder. A single layer electrode structure has been developed for certain applications of the aluminum-air battery, combining both hydrophobic and hydrophilic properties to provide a balance between oxygen transport and electrolyte penetration to the catalyzed sites. ${ }^{33}$

The use of platinum as catalyst for the oxygen reduction reaction has been shown to promote corrosion of the carbon substrate and significantly shorten the operating life of the cathode. ${ }^{34}$ The research programs at CWRU identified several transition metal macrocycles to be effective catalysts and, in particular, cobalt tetramethoxyphenylporphryn (COTMPP) showed excellent activity and stability. Furthermore, this catalyst did not enhance the substrate carbon corrosion as did platinum. It is believed that in the pyrolysis of the macrocycle to form the catalyzed carbon a "new carbon" 


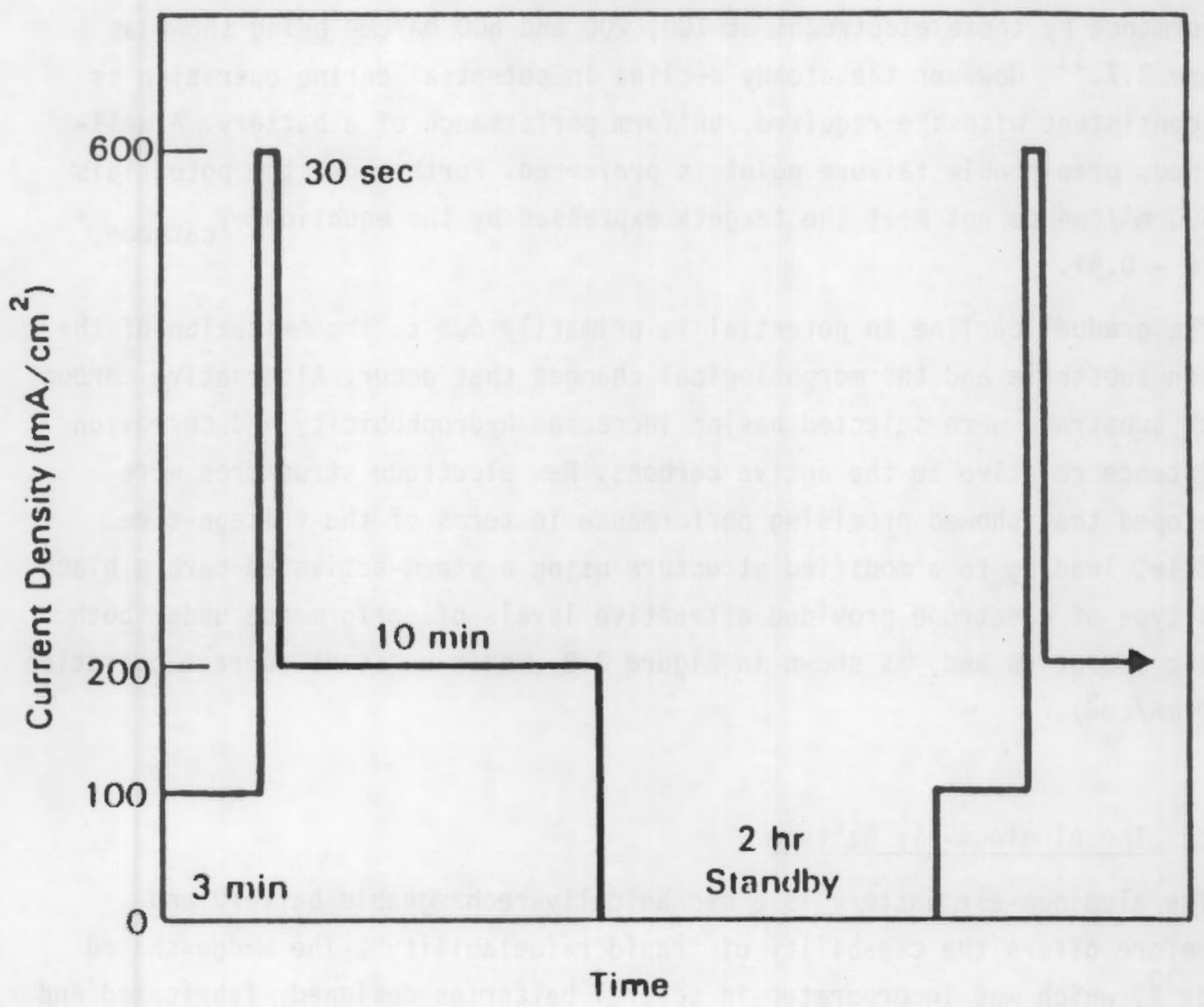

Electrolyte Drained.

Air Flow Halted on Standby

FIGURE 3.6: Drive Cycle Under which the Air Cathodes are Tested 
structure is formed which is more resistant to oxidation that the substrate. ${ }^{35}$

Improvements were made in the electrode structure and fabrication, e.g., the development of superior binder materials and the classification of the carbon substrate in terms of an optimum range of particle sizes. Stable operation over 2000 drive cycles has been demonstrated, the levels of performance by these electrodes at 100,200 and $600 \mathrm{~mA} / \mathrm{cm}^{2}$ being shown as Figure $3.7 . .^{33}$ However the steady decline in potential during operation is not consistent with the required, uniform performance of a battery. A welldefined, predictable failure point is preferred. Furthermore the potentials at $600 \mathrm{~mA} / \mathrm{cm}^{2}$ do not meet the targets expressed by the equation $V_{\text {cathode }}=$ $0.876-0.4 i$.

The gradual decline in potential is primarily due to the oxidation of the carbon substrate and the morphological changes that occur. Alternative carbon black substrate were selected having increased hydrophobicity and corrosion resistance relative to the active carbons. New electrode structures were developed that showed promising performance in terms of the voltage-time profile, leading to a modified structure using a steam-activated carbon black. This type of electrode provided attractive levels of performance under both cyclic operation and, as shown in Figure 3.8, under constant current operation $\left(450 \mathrm{~mA} / \mathrm{cm}^{2}\right)$.

\subsubsection{The Aluminum-Air Battery}

The aluminum-air battery is a mechanically-rechargeable battery and therefore offers the capability of "rapid refuelability". The wedge-shaped anode ${ }^{30}$, which was incorporated in several batteries designed, fabricated and operated at Lawrence Livermore National Laboratory ${ }^{28}$, could provide essentially continuous refueling. Maimoni et al operated a battery of this design for a period of "almost nine hours; enough time to indicate satisfactory perfornance of the cell components but not enough time to suggest long-term problems". ${ }^{36}$

Within the programs sponsored by the Department of Energy and coordinated by Eltech Research Corporation, the transition from component evaluation to the design and evaluation of the battery began in 1985. Modification to the M-4 cells developed at LLNL led to the design, fabrication and operation of a 


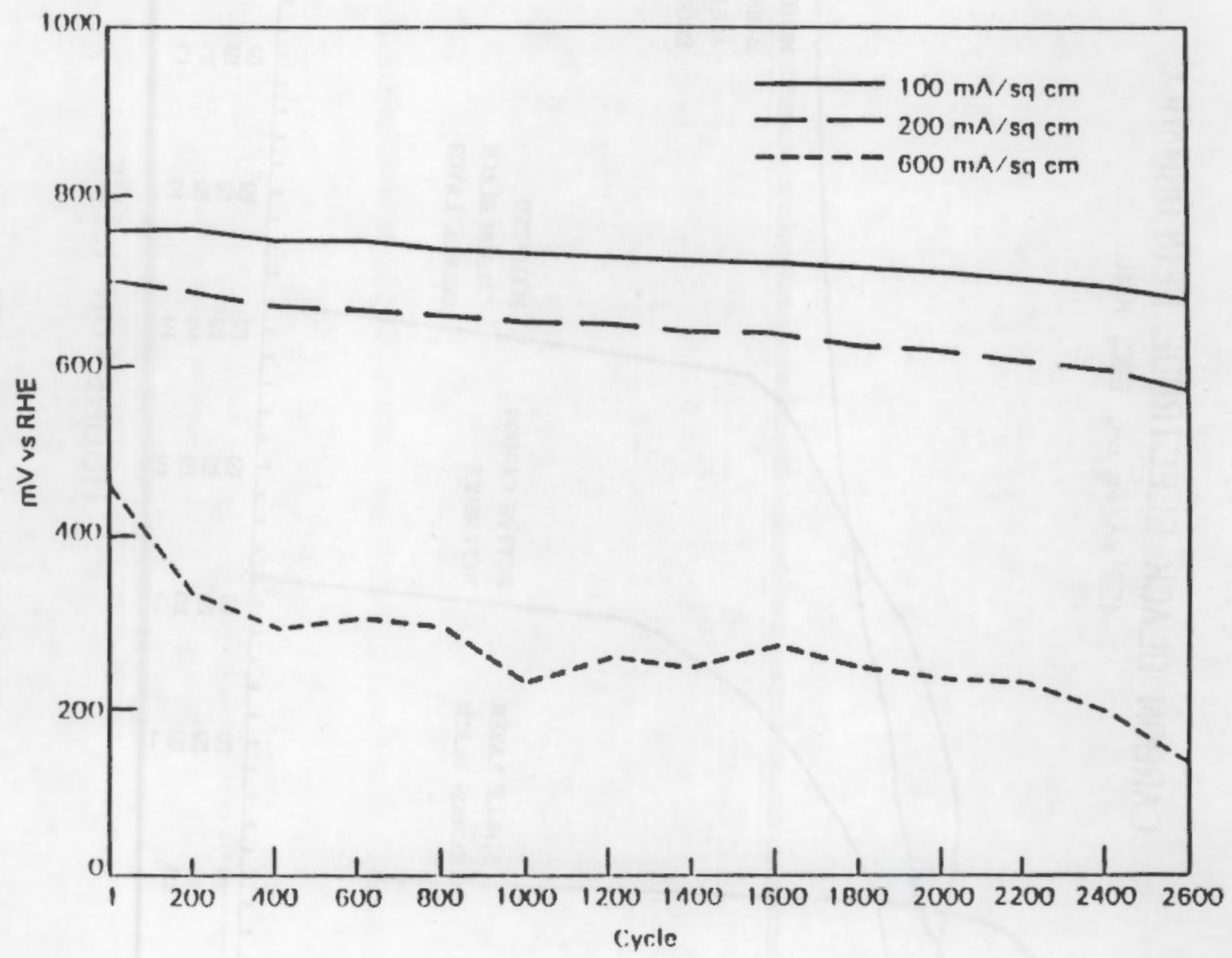

FIGURE 3.7: Voltage as a Function of Drive Cycles for a Co(TMPP) Catalyzed Air Electrode at the Current Densities 


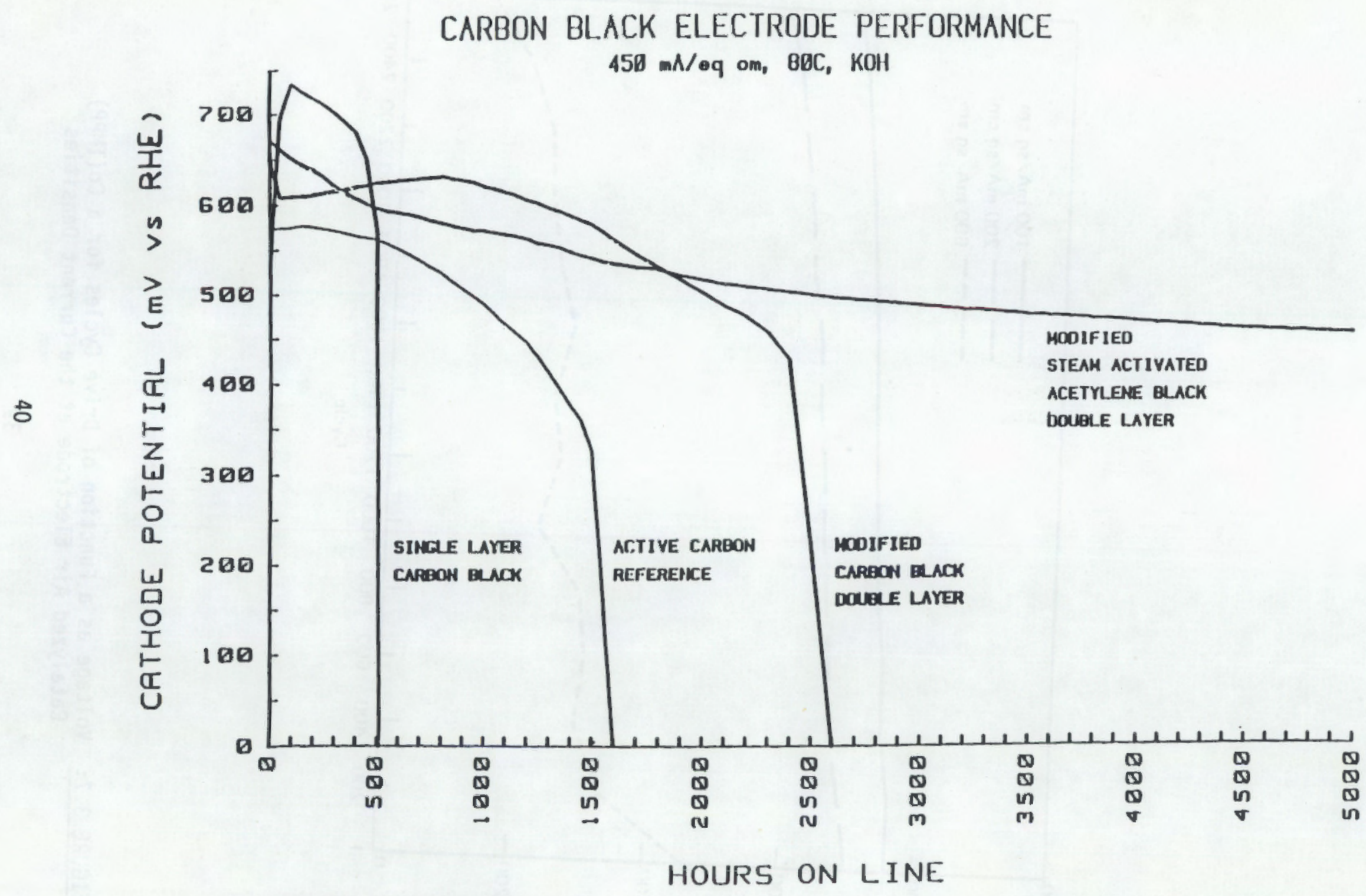

FIGURE 3.8: Carbon Black Electrode Performance 
cell designated as EL-1. The wedge-shaped anode was retained but significant improvements were made to both the electrolyte and air distributors. A modular air cathode was developed to allow easy handling and assembly and to facilitate current collection. Operation of the EL-1 yielded short-term data consistent with performance projected from component testing. Data obtained using ultrapure aluminum as the anode and a CoTMPP catalyzed air cathode is shown as Table 3.2.

Table 3.2

Operation of the EL-1 Cell

Current Density

$9 \mathrm{~mA} / \mathrm{cm}^{2}$ )

Cell Voltage (volts)

Measured Predicted

\begin{tabular}{|c|c|c|}
\hline 100 & 1.54 & 1.53 \\
\hline 200 & 1.34 & 1.34 \\
\hline 300 & 1.16 & 1.15 \\
\hline 400 & 1.00 & 0.99 \\
\hline 470 & 0.88 & 0.83 \\
\hline Electrolyte: & $4 \mathrm{M} \mathrm{NaOH}$ & \\
\hline Temperature: & $60^{\circ} \mathrm{C}$ & \\
\hline Electrolyte Flow: & 3 gallons/minute & \\
\hline Anode-Cathode Gap: & $2 \mathrm{~mm}$ & \\
\hline
\end{tabular}

However, a uniform rate of feed of the edge anode was not obtained and problems were identified with the solution-side current collectors.

Modelling studies carried out at Case Western Reserve University (R. Savinell) indicated that external current collection from the anode was feasible. Redesign of the EL-1 cell was undertaken at Eltech and a high quality, external connector, between the partially dissolved anode and the refuel anode, was developed. Further modifications were made to the electrolyte distributor. ${ }^{37}$ An "anode basket" replaced the original plastic tines (Figure 3.9), providing support to the falling anode and fixing the electrolyte gap with a dielectric material.

The EL-2 cell design did resolve several of the problems that had been 


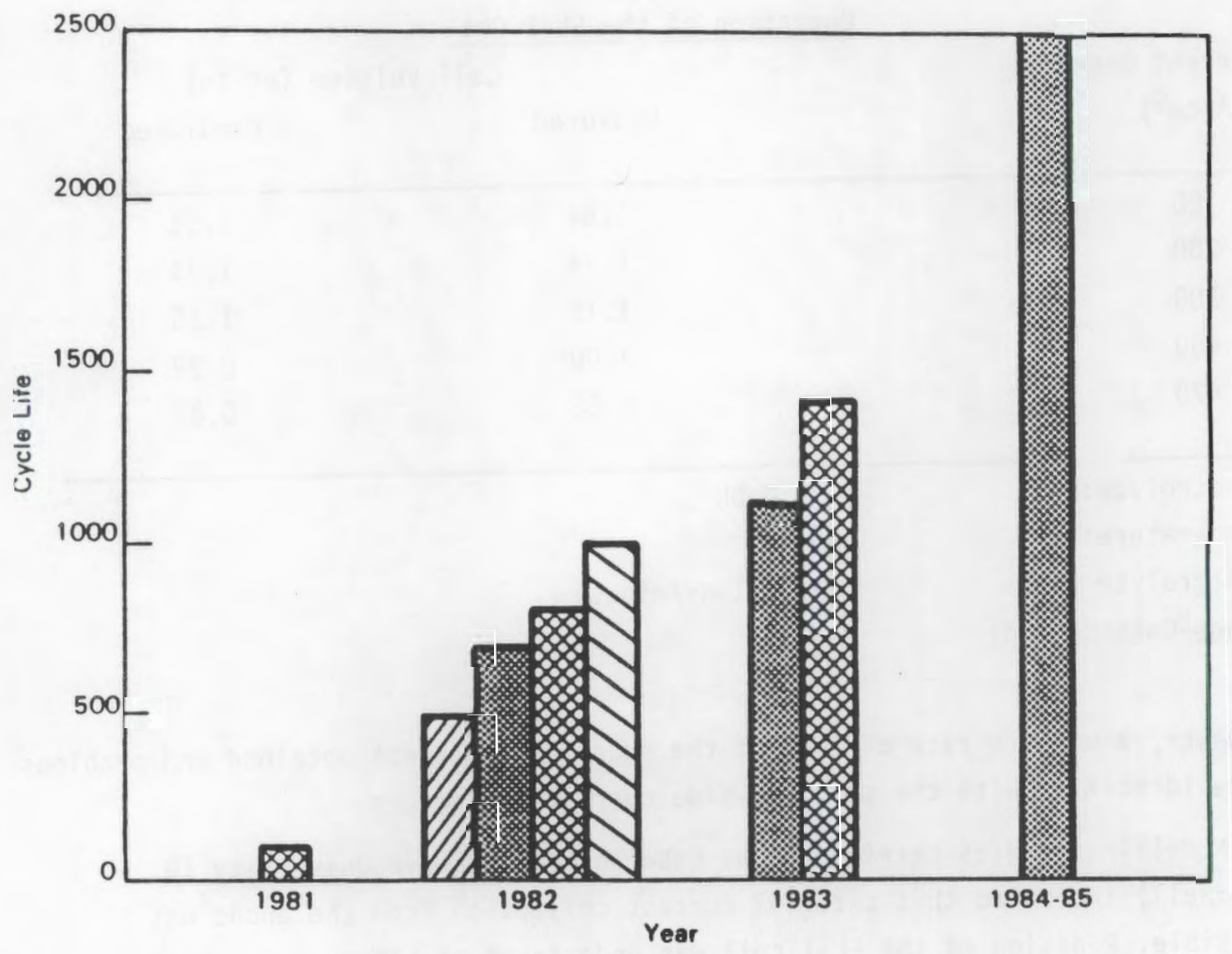

FIGURE 3.9: Improvements with Time in the Cycle Life of Air Cathodes for the Aluminum-Air Battery 
experienced with the M-4 and EL-1 cells. However, gravity feed, or simply the concept of a moving, electrochemically active electrode, presents a difficult electrochemical engineering problem. Although refuelability was demonstrated the movement of the anode was uneven and further design changes appeared necessary. Even should such changes prove successful it was recognized that two major problems existed with the EL-1 and EL-2 cells:

1. Both were unsealed cells.

2. The volume and weight of the cells were too large.

Being unsealed the electrolyte, hydrogen gas or caustic mist may be released into the vehicle. This was an unacceptable situation, probably leading to damage to the process equipment and vehicle, and certainly representing a hazard to the operator or to an attendant who services the vehicle. It was also evident that changes in the orientation of the vehicle and the vibrations of normal travel may cause electrolyte spillage.

The weight of the EL-2 was approximately 7.9 kilograms and it occupied a volume of 10 liters (including the refuel anode). Thus a 100 volt stack would occupy 720 liters and weigh 545 kilograms and this did not include any other equipment.

The design and development of a lightweight and compact battery was undertaken at Eltech Research Corporation independently from the ongoing DOE programs. Several criteria were considered ${ }^{38}$ :

1. Reduced weight and volume

2. Refuelability

3. Modular Air Cathode

4. Planar anodes

5. Internal current distribution from cell to cell

6. Minimum sensitivity to orientation

This approach has led to the construction and preliminary evaluation of the 
B-300 cell, shown as Figure 3.10, with a volume of 1.1 liters and weight of 1.3 kilograms, and having an active electrode area of $300 \mathrm{~cm}^{2}$. It is this cell that will be used in the initial phases of the jointly funded program between Eltech and Sandia National Laboratories.

\subsubsection{Electrolyte Management System}

A key component of the electrolyte management system is the crystallization process for the hydragillite. One approach taken so far has assumed that the hydragillite particles have to grow to at least 40 micron size so that they can be used as feedstock in the Hall-Heroult cell to produce aluminum metal. However, to accomplish this goal the electrolyte management system became more complicated. The lamella settler and agglomerators considered for this purpose not only cause vehicle packaging problems but are susceptible to vibrations, which would be commonly encountered during the operation of a vehicle. Furthermore the presence of the multiple pumps and flow loops associated with the crystallizer would reduce the overall reliability and power output by increasing the parasitic power required to operate the system.

If the restriction on the particle size is relaxed, the complexity of the electrolyte management system can be significantly reduced. A study on the crystallization kinetics of aluminate at ALCAN indicates that hydragillite formation is greater than the rate of crystal growth. Without any special provisions in the electrolyte management system, like the agglomerator, the typical crystallite size is expected to be ten microns. If separation devices can be developed to remove ten micron size particles, a simplified electrolyte management system can then be considered as shown in Figure 3.11. Periodically (approx. $400 \mathrm{~km}$ ) the electrolyte from the tank is removed at a service station, filtered to remove the solids and is returned to the vehicle. It is accepted that the 10 micron alumina particles will be unusable in a Hall-Heroult cell. However, the fine aluminum particles may be used in markets in which alumina is presently used, or alternatively can be disposed of in landfills with relative ease. A better definition of this approach is required.

As stated earlier, it has been shown that the kinetics of crystallization may be significantly affected by the presence of the alloying elements of the 


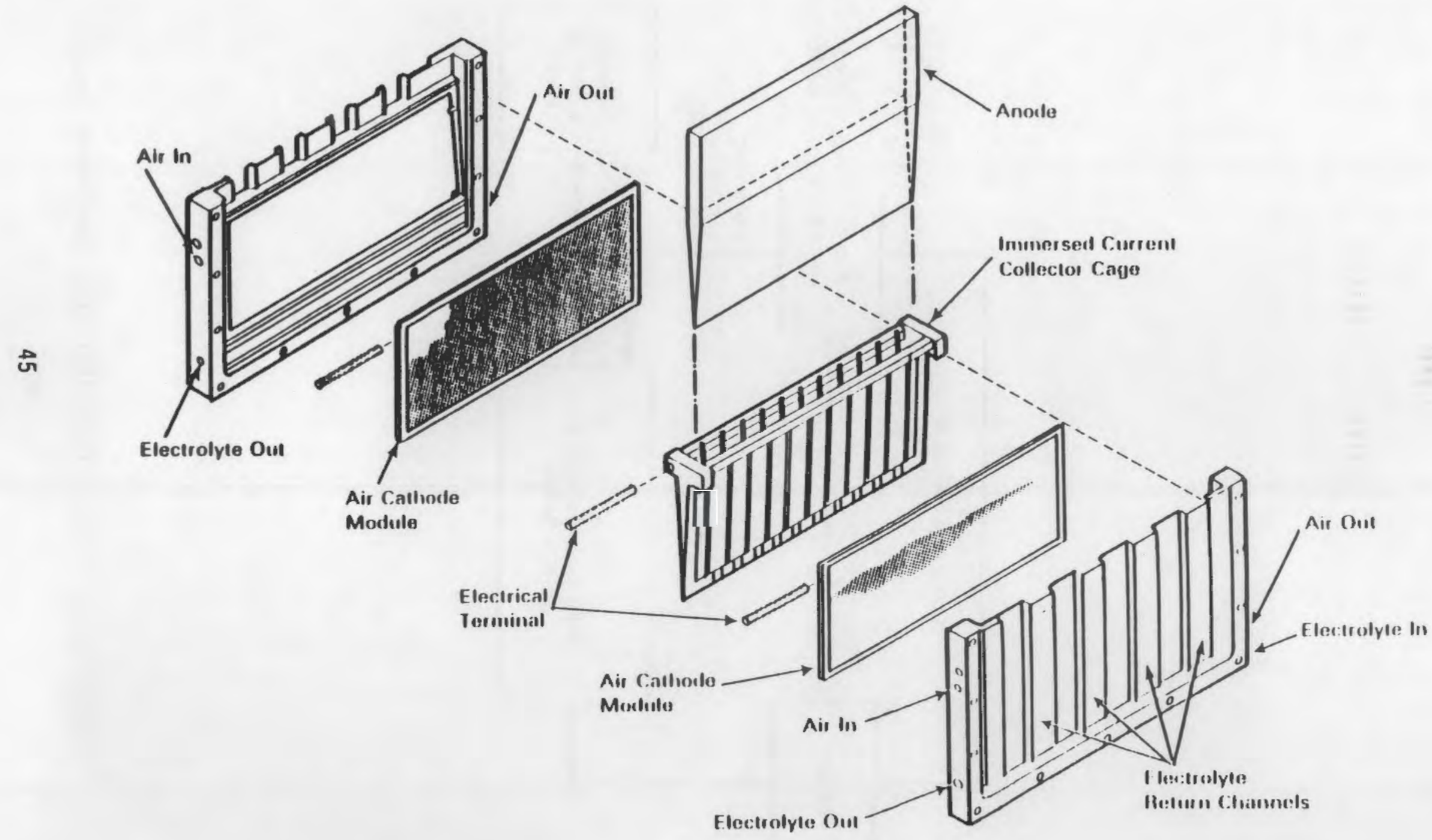

FIGURE 3.10: Schematic of the Eltech Systems Corporation EL-2 Cell 


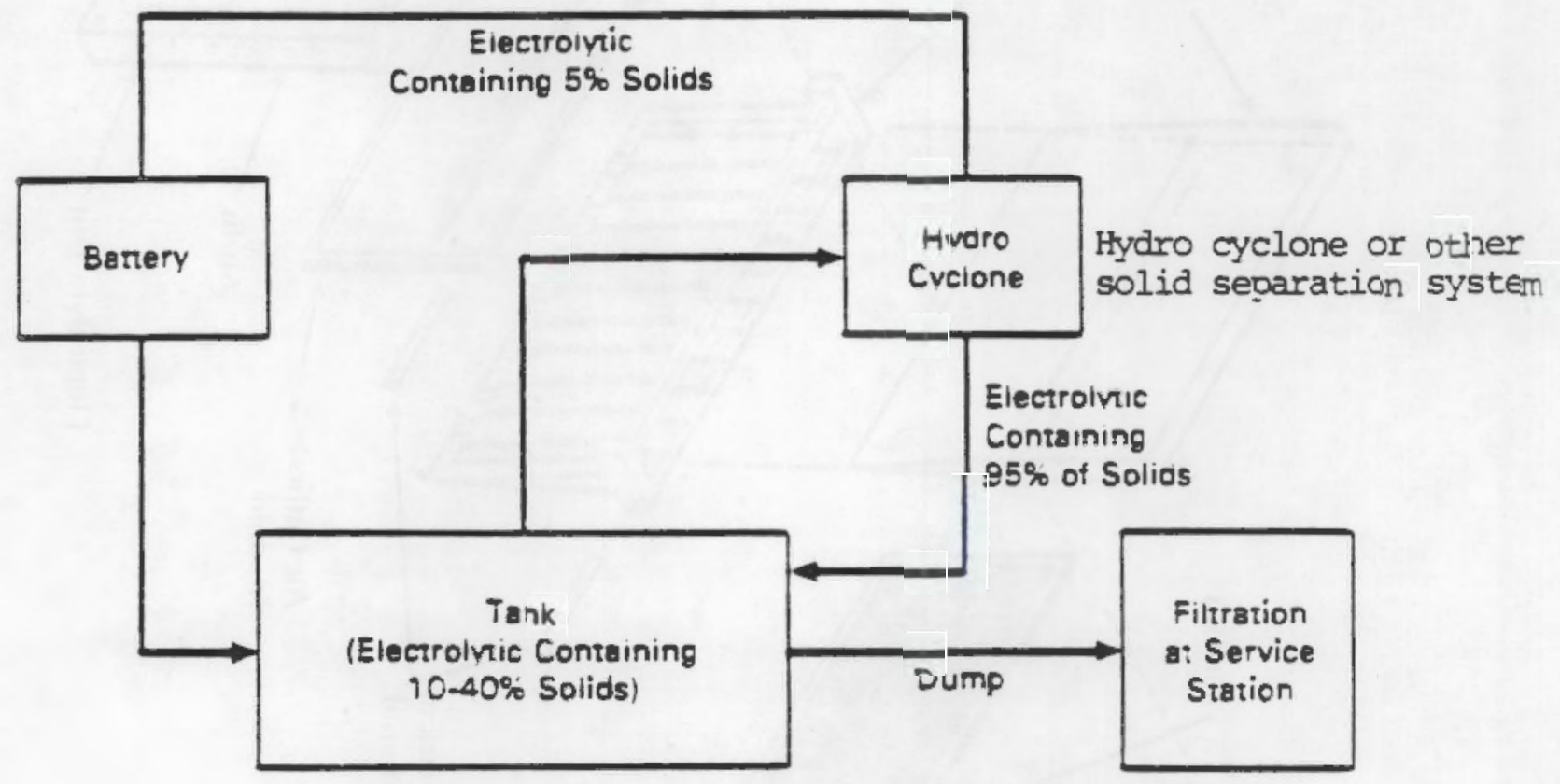

FIGURE 3.11: A Simplified Electrolyte Management System 


\begin{abstract}
aluminum anode in the electrolyte. If these results are confirmed, the number of alloys that may be considered as viable candidates for the aluminum-air battery will be limited. This interaction between the battery and the electrolyte management system illustrates the need for close coordination of research on these two components.
\end{abstract}





\subsection{IRON-AIR BATTERY}

\subsection{GENERAL CONSIDERATIONS}

The overall cell reactions in an iron-air battery are:

Iron Electrode

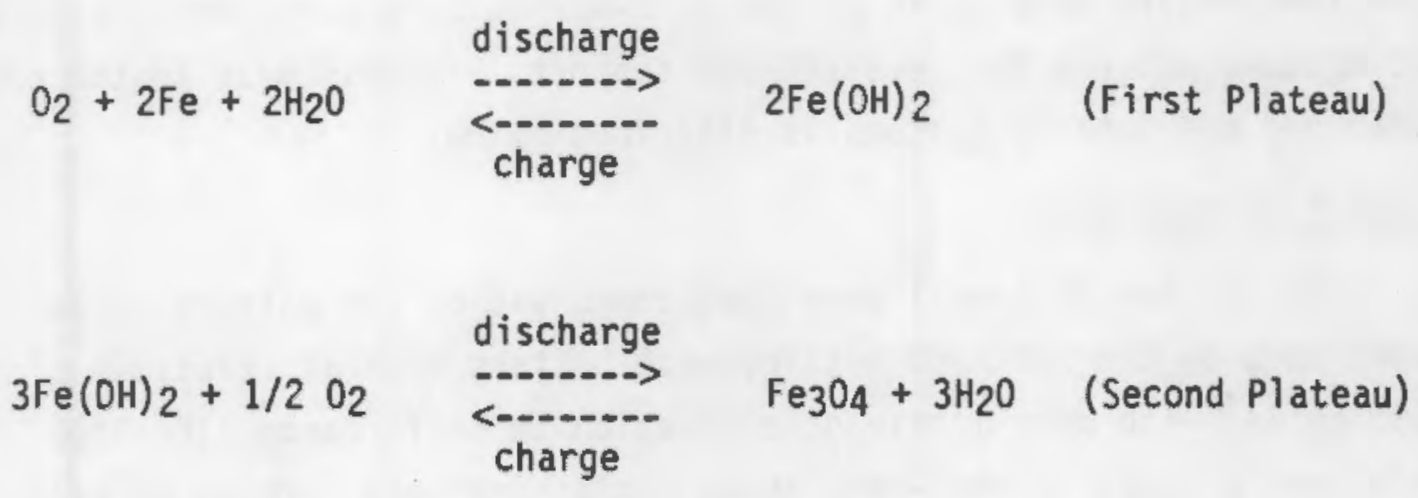

Air Electrode

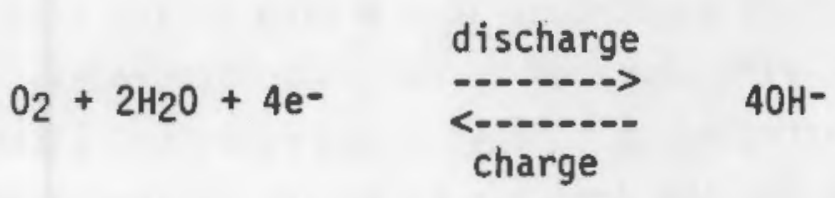

The iron-air battery is a electrically rechargeable secondary battery system. Its specific energy is lower than the mechanically rechargeable systems discussed in the previous sections, but has potentially a lower life cycle cost. The iron electrode shows extremely reproducible behavior over many cycles and does not exhibit any redistribution of active materials or gross shape changes (as is observed with zinc electrodes) on repeated cycling.

The single most important limiting factor in this battery is the bifunctional air-electrode. This electrode evolves oxygen during charge and reduces oxygen to $\mathrm{OH}^{-}$during discharge. Hydrogen peroxide is usually produced as an intermediate during the discharge process. The oxygen and hydrogen peroxide produced at the electrode promotes the corrosion of the carbon 
substrate, loss of the catalysts and the subsequent delamination of the electrode. As a result, long cycle life on the air-electrode is difficult to achieve. The use of a separate air electrode for charge and discharge is not impractical, due to the weight and volume requirements of the bi-functional air-electrode.

\subsection{PRESENT DEVELOPMENT STATUS}

The Swedish National Development Corporation (SNDC) and Westinghouse have been the primary developers of the iron-air battery over the last decade. The Westinghouse program has received DOE support. Progress made in the battery components and the battery systems is described below.

\subsubsection{The Iron Electrode}

This is the most well developed component of the battery. Iron electrodes used by the SNDC and Westinghouse battery exhibit lifetimes of over 1000 cycles with very little deterioration in performance. The SNDC electrode uses a sintered iron-mesh anode containing pore forming material to optimize the reactive surface of the electrode resulting in $65 \%$ material utilization. The Westinghouse electrode is similar to the SNDC electrode with the exception of the steel mesh. These electrodes have a high active iron content and a somewhat lower cycle life compared to the SNDC electrodes. Electrodes of this type have demonstrated up to $0.44 \mathrm{Ah} / \mathrm{gm}$ capacity. Either of these anodes are quite suitable for the iron-air batteries contemplated for electric vehicle application.

\subsubsection{The Bi-Functional Air-Electrode}

The bi-functional air-electrode is the weak link in the development of the iron-air battery. The SNDC battery uses an air-electrode made of a porous nickel, composed of sintered nickel of coarse and fine porosities in a double layer structure $(0.6 \mathrm{~mm}$ thick). The coarse layer facing the electrolyte is impregnated with a silver catalyst to promote the reduction of oxygen. Hydrophobic agents are also added to the coarse layer to prevent electrode flooding. SNDC has reported 1000 cycles with this type of electrode. However, the electrode performance deteriorates with increased cycling and the cost is high for electric vehicle application. 
In contrast, the Westinghouse electrode is a multilayered, teflonbonded, carbon based structure with a complex catalyst system containing Ag, $\mathrm{Co}$ and $\mathrm{Ni}$. The electrode is supported on a silver plated nickel screen. This is potentially a low cost electrode having acceptable voltage performance, however cycle life is limited. Electrodes at Westinghouse have shown lifetimes of approximately 500 cycles, whereas the electric vehicle application would require a life time of at least 1000 cycles.

\subsubsection{The Battery}

A schematic of the SNDC $30 \mathrm{KWH}$ battery is shown in Figure 4.1. Electrolyte circulation is used to control heat balance and remove gasses generated during operation. Carbon dioxide is removed from the incoming air by using a sodium hydroxide scrubber. The air is then humidified in a moisture exchange. Overall, the auxiliary system requires less than $10 \%$ of the system output.

Typical charge-discharge of the SNOC cell is shown in Figure 4.2. The marked difference in charge-discharge curves voltage results mainly from the low overall system efficiency. This system is capable of over 1000 cycles with gradual deterioration of the air electrode performance.

Most of the development effort at Westinghouse has been at the cell and module level. Based on the performance, projections have been made by Westinghouse regarding the electrode characteristics and module performance of the iron-air battery. These are shown in Table 4.1. The power characteristic of a typical Westinghouse aluminum-air cell is shown in Figure 4.3.

TABLE 4.1 Module Characteristics of a Westinghouse Iron-Air Battery

Cell Weight
5 Cells
Electrolyte-Gas Manifold
Interconnectors
Volume
Total Module Weight
Energy Content
Peak Power
Power Density
Vol. Energy Density

Cell Weight

Electrolyte-Gas Manifold

Interconnectors

Volume

Total Module Weight

Energy Content

Power Density

Vol. Energy Density
$40 \mathrm{~g}$

$2700 \mathrm{~g}$

$170 \mathrm{~g}$

$50 \mathrm{~g}$

3.51

$2920 \mathrm{~g}$

$322 \mathrm{Wh}$

260 W 0400 Amps

$90 \mathrm{~W} / \mathrm{Kg}$

$.13 \mathrm{KWh} / 1 \mathrm{it}$ 

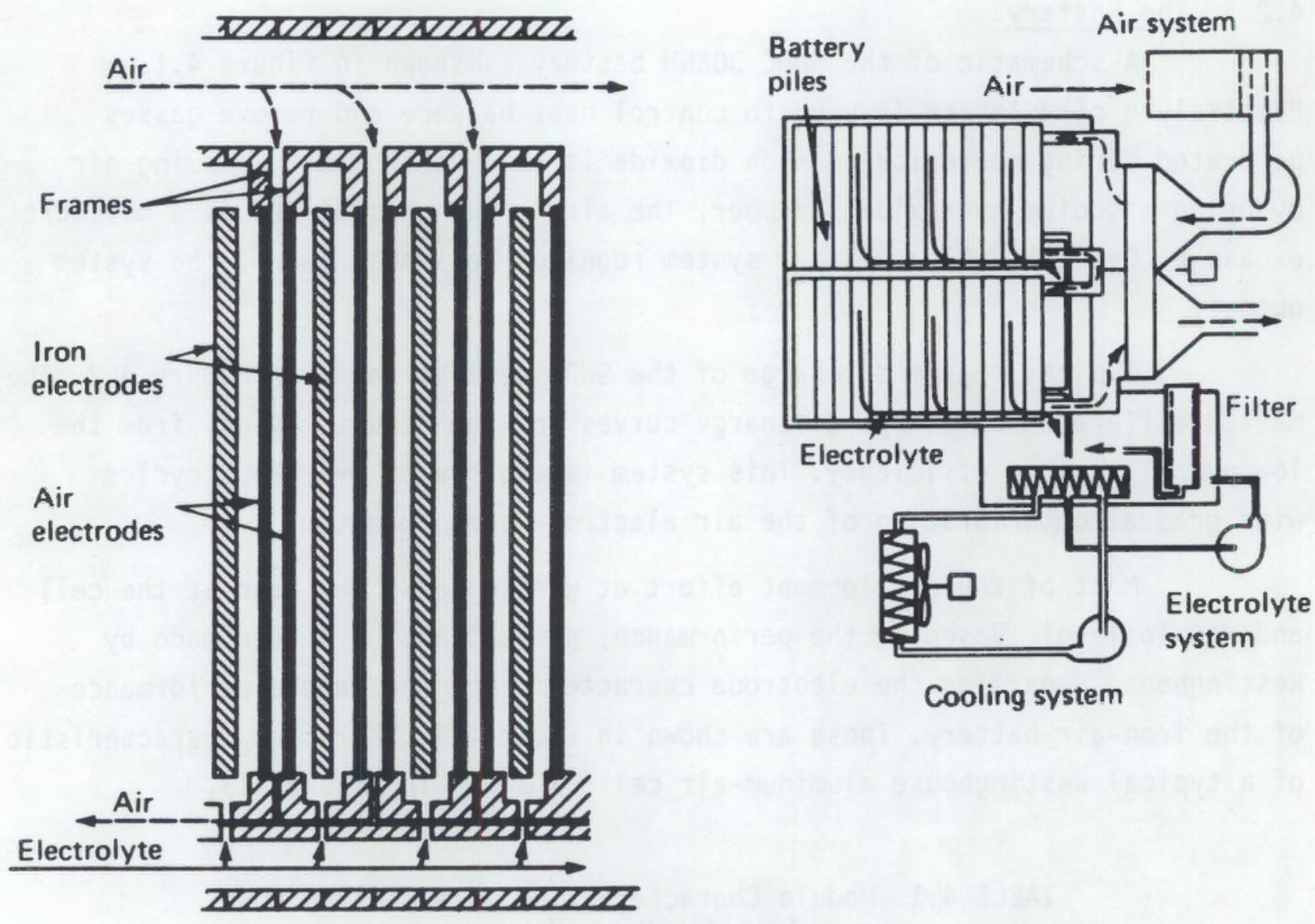

FIGURE 4.1: Schematic of a Swedish National Development Corporation Iron-Air Battery 


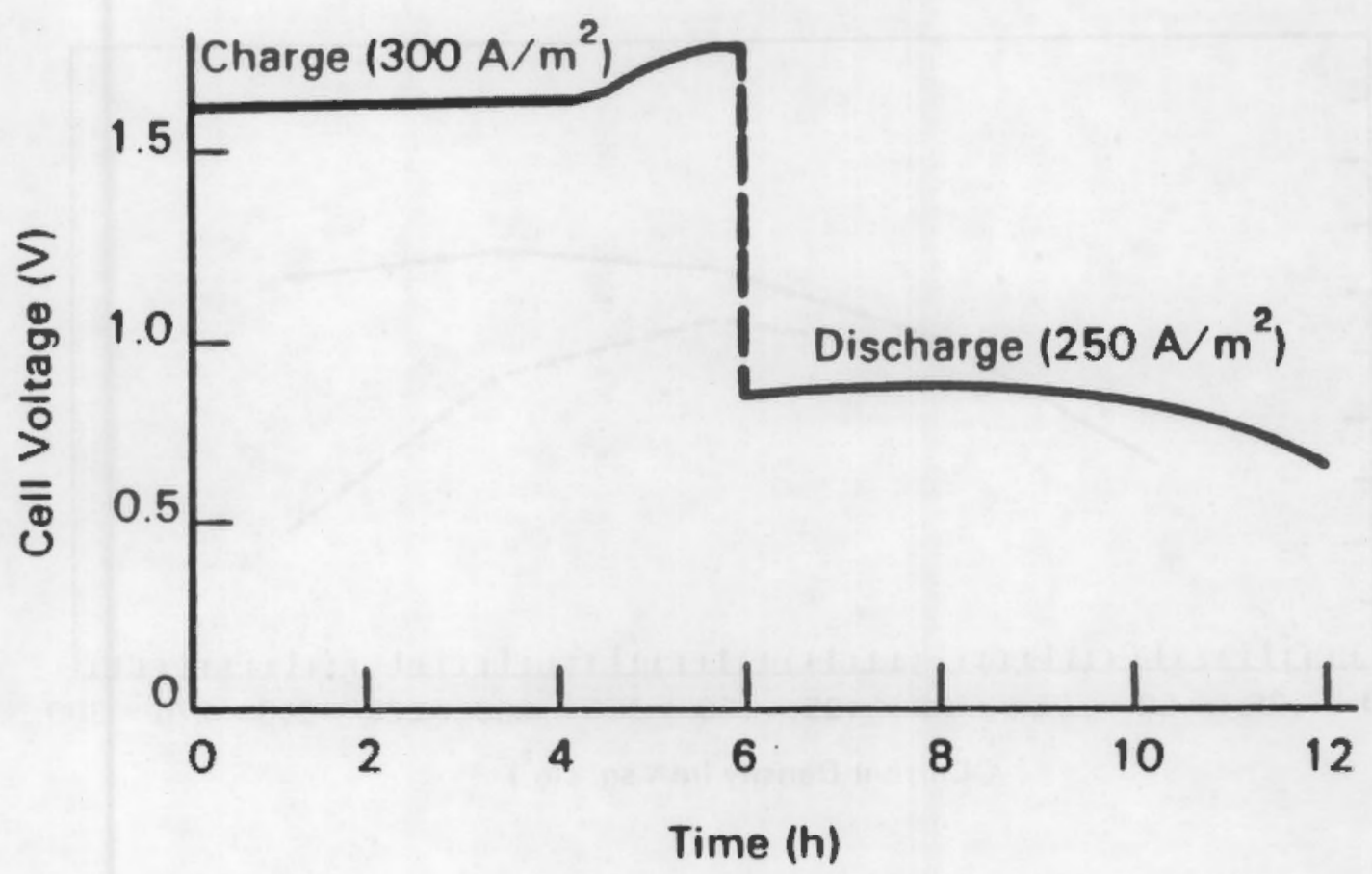

FIGURE 4.2: Charge-Discharge Performance of the SNDC Battery 


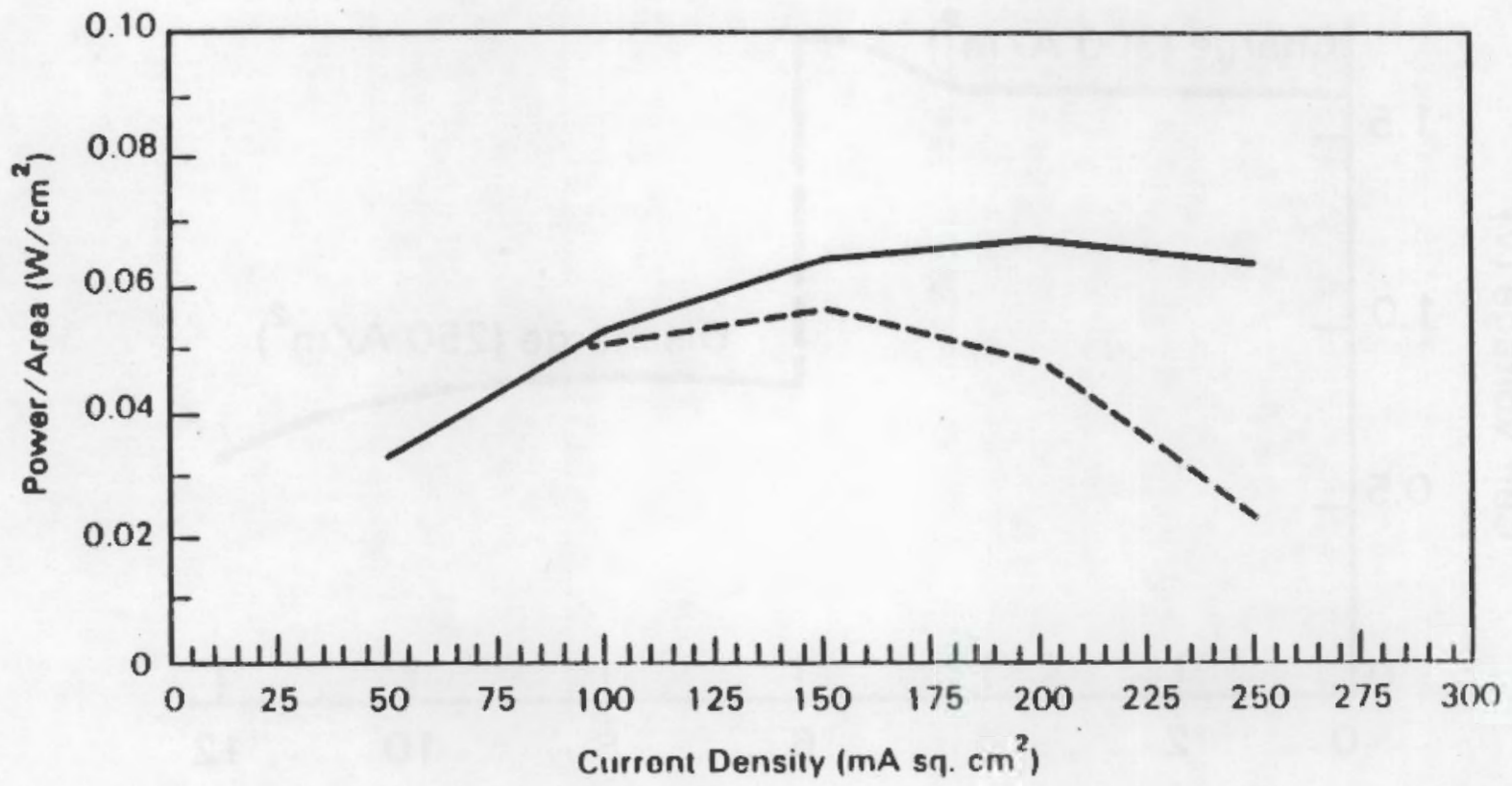

FIGURE 4.3: Power Characteristics of a Westinghouse Iron-Air Cell 


\subsection{MONO/BI-FUNCTIONAL AIR ELECTRODE}

\subsection{The Air Cathode}

The oxygen cathode which reduces oxygen to hydroxyl ions in an alkaline media is a common feature of the aluminum-air, mechanically rechargeable and the circulating zinc-air battery systems. ELTECH Systems Corporation has been the primary developer of alkaline air-electrodes in recent years with the basic research being conducted at Case Western Reserve University. Considerable progress in developing cost-effective high performance electrodes has been obtained over the last several years. Platinum has been replaced with cobalt tetramethoxy-phenyl-porphyrin as the catalyst, lowering cost without sacrificing performance even at high current densities of $600 \mathrm{~mA} / \mathrm{cm}^{2}$. The use of Norit carbon as the substrate material has reduced carbon corrosion, especially under open circuit conditions, and have significantly increased cathode life. ELTECH has demonstrated cycle life of 3000 cycles which Lawrence Livermore Laboratory estimates to correspond to a four year life under actual vehicle operating conditions (approximately $3000 \mathrm{cycles}$ ). Continuous testing of these types of electrodes at current densities of $400 \mathrm{~mA} / \mathrm{cm}^{2}$ has proceeded for several months without degradation of the electrode or the voltage performance.

An important finding has been determined that the performance of the air-cathode is substantially superior in a $\mathrm{KOH}$ solution than in a $\mathrm{NaOH}$ solution. ${ }^{39}$ Figure 5.1 shows the voltage performance of a cobalt tetramethoxy phenyl porphyrin catalyzed Norit carbon electrode as a function of cycling in $\mathrm{NaOH}$ and $\mathrm{KOH}$ at $600 \mathrm{~mA} / \mathrm{cm}^{2}$. A 200 to $250 \mathrm{mV}$ advantage is observed with the $\mathrm{KOH}$ electrolyte over 1000 cycles. This result should be of interest to the zinc-air battery development effort, since a change of the electrolyte from $\mathrm{NaOH}$ to $\mathrm{KOH}$ should be seriously considered.

Despite the overall progress in air-cathode research, some serious areas of concern remain. These are: 


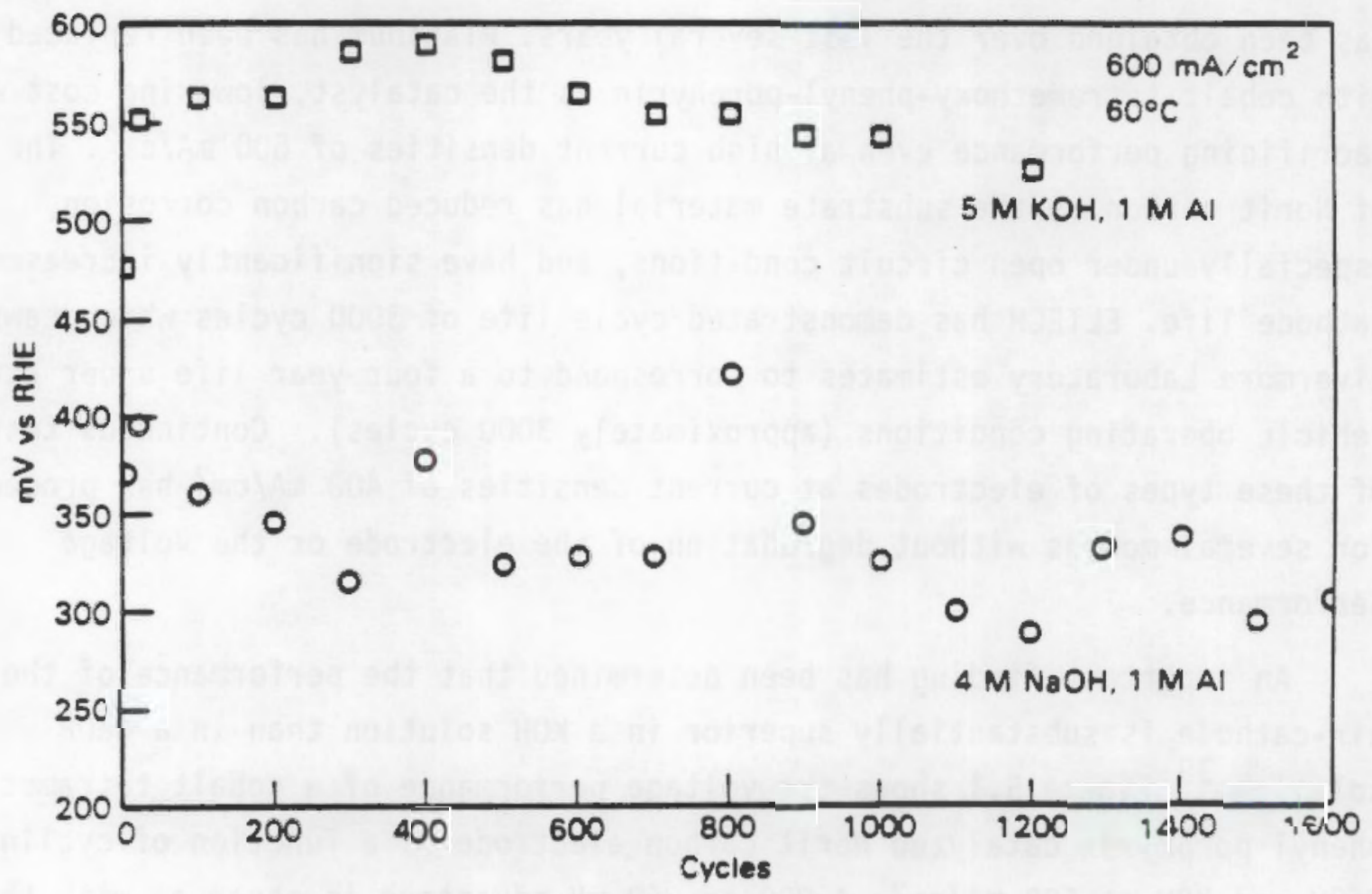

FIGURE 5.1: Performance of a CO(TMPP) Catalyzed Norit Carbon Electrode at $600 \mathrm{~mA} / \mathrm{cm}^{2}$ in $\mathrm{NaOH}$ and $\mathrm{KOH}$ 
1) ELTECH acknowledges that with the cobalt tetramethoxy phenyl porphyrin catalyst, a certain amount of cobalt is lost from the electrode. The loss is apparently appreciable in the first several hours of operation and then slows down considerably. This cobalt introduced into the electrolyte can deposit on either the aluminum or zinc electrodes and accelerate the unwanted chemical corrosion process, lowering the efficiency of the system and producing more hydrogen gas. The cobalt in the electrolyte could probably seriously hinder the zinc regeneration step during the charging cycle of the zinc-air battery. Currently, it is not clear how significant these problems are.

2) The simulated drive cycle established by LLNL in conjunction with ELTECH Systems Corporation was an effort to develop an accelerated and stringent test of air-cathode performance. The optimization of electrode performance has been targeted towards the performance required by the drive cycle. However, this simulated drive cycle is significantly different from standardized drive cycles, e.g. FUDS. The performance of the air cathodes could be quite different when tested under a FUDS cycle. Since FUDS represents a good description of the urban drive cycle, it would be important to test the airelectrodes under these conditions. For the case of aluminum-air battery the FUDS cycle should be modified to incorporate the extended range capability of the battery. Such testing would be beneficial to both the aluminum-air and zinc-air battery development program.

3) The impact of impurities entering the electrolyte from the alloying agents of aluminum, additives in zinc, and the slow carbonate buildup due to incomplete removal of $\mathrm{CO}_{2}$ from the air could impact the performance of the air-cathode. A program to define and test these effects is therefore warranted.

4) The reproducibility of the air-cathode performance from batch to batch is poor. Efforts to accomplish this have been initiated at ELTECH and are key to the successful development of both the aluminum-air and zinc-air battery systems. 


\subsection{The Bi-Functional Air-Electrode}

The bi-functional air-electrode is an important component of conventional secondary zinc-air and iron-air batteries. In recent years bi-functional airelectrode development has been pursued in the U.S. by Westinghouse as part of their iron-air battery development effort. Basic research is ongoing at Case Western Reserve University and Lawrence Berkeley Laboratories to understand the behavior of these electrodes. A large volume of literature also exists where different catalyst systems and substrate materials have been evaluated with varying degrees of success.

A bi-functional air-electrode requires the following key ingredients:

- Catalyst promoting the evolution of oxygen

- Catalyst promoting the reduction of oxygen

- Substrate material that is resistant to corrosion during oxygen evolution and reduction.

It would be ideal if one catalyst could perform the dual role required. No such catalyst currently exists that exhibits long cycle life. The substrate materials are also a problem area. The most commonly used substrate is based on some form of carbon, which tends to corrode at unacceptable rates during the anodic evolution of oxygen. The goal of finding suitable catalysts and substrate material is indeed formidable.

The Westinghouse electrode which has exhibited probably the longest cycle life of any bi-functional air-electrode ( 500 cycles) employs a complicated catalyst system consisting of silver, nickel, iron and tungsten on a carbon substrate. Considerable work has been done to optimize this structure/catalyst system to achieve the goal of 1000 cycles. The effort so far has not been successful. A failure mechanism analys is of this type of electrodes conducted by Case Western Reserve University came to the following conclusions:

- Carbon oxidation is thought to be the major factor contributing to the degradation of electrode performance.

- XPS studied showed that the $0 / C$ and $\mathrm{Fe} / \mathrm{C}$ ratios increased markedly during extended cycling, indicating oxidation and loss of carbon. 
- SEM and weight loss results also supported the carbon loss observation.

- Teflon, used as a binder, is also subjected to surface oxidation.

Recently progress has been made to identify promising catalyst and substrates for bi-functional air-electrodes under DOE sponsorship. Energy Research Corporation demonstrated a perovskite catalyzed electrode could be cycled over 800 cycles at $10 / 20 \mathrm{ma} / \mathrm{cm}^{2}$ (charge/discharge) with stable overpotential of $600 /-280 \mathrm{mV} v \mathrm{Hg} / \mathrm{HgO}$ reference electrode. The performance of these electrodes is not very different from the Westinghouse electrodes, although the current densities are low.

At Lawrence Berkeley Laboratories a heat treatment procedure for therma blacks has been developed which produces a carbonaceous material with significantly enhanced corrosion resistance. This material could be a suitable substrate material for bi-functional air-electrodes.

It must be mentioned that the promising results indicated above are still preliminary. Basic research to develop catalyst and substrates for bifunctional air electrodes should continue. Less emphas is should be placed on electrode structure and optimization until good progress on the characteristics of the substrate and catalyst system has been made. Success in developing an effective bi-functional air electrode will dramatically improve the chances of developing both the iron-air and zinc-air batteries for electric vehicle application. 
$\cdot$

,

- 


\subsection{COMPARISON OF METAL/AIR BATTERIES}

Table 6.1 compares the advantages/disadvantages and the prospects of metal-air batteries being successful in electric vehicle application. The iron-air system appears to be promising for fleet vehicle applications if a breakthrough in the bi-functional air electrode is achieved. This, however, is a formidable technical challenge. The aluminum-air and circulating slurry zinc-air battery are attractive candidates for a general purpose electric vehicle, however, both systems are quite complex and vehicle packaging and reliability will be a significant problem with these systems. These two batteries will require a complex new infrastructure to be developed for servicing the batteries. The infrastructure could turn out to be more complex with aluminum-air than with the zinc-air battery.

In considering metal-air batteries for electric vehicle application it is necessary to compare the efficiencies of these batteries versus other types of EV batteries under development. The best advanced secondary batteries under development for EV applications (such as sodium-sulfur) will have electric to electric efficiencies in the range of $65 \%$. The corresponding efficiencies for the circulating slurry zinc-air and the aluminum-air battery are $42 \%$ and $30 \%$ respectively. Research on promising metal-air batteries thus cannot be justified on the basis of efficiency alone. The potential for higher performance than alternate batteries is the primary advantage of the aluminum-air and the zincair batteries. The criteria, therefore, that can be used with metal-air batteries would have to be that their overall efficiencies (i.e. coal to road) must be better than internal combustion engines powered by coal-derived synthetic fuel. This efficiency is expected to be in the range of 10 to $12 \%$. The best estimates of coal to road efficiencies for circulating slurry, zincair and aluminum-air are in the range of $10-15 \%$. The metal-air batteries thus have the potential of being more efficient than an ICE powered by synthetic fuel. 
TABLE 6.1

Comparison of Metal-Air Batteries

Battery Type

A luminum-Air

Iron-Air

\section{Present Status}

Research on components in progress.

Integrated system

not yet

demonstrated.

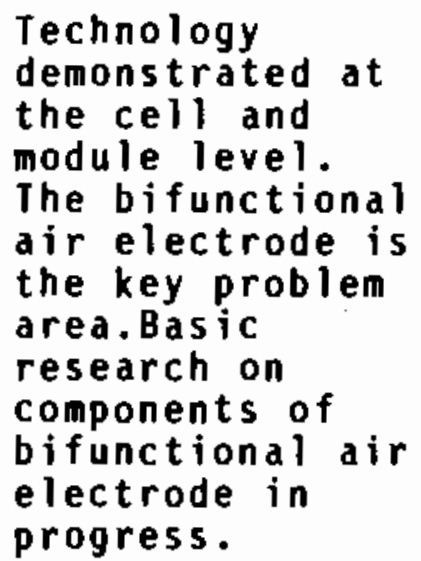

No known development efforts.

\section{Advantages}

\author{
Rapid \\ refuelability. \\ Energy \\ density.Long \\ range.
}

Low cost. Long cycle life.

Low energy

density.

Limited range.

Complex system.

Low energy

efficiency.

Cost.

Complex

infrastructure.

Compact system. Low cost.

\section{Prospects}

High rate, long term project

with the potential

for acceptance as

the power source

for a general

purpose EV with performance comparable to an ICE engine.

Breakthrough in bifunctional air electrode technology required. Potential for a rugged, long cycle life rechargeable system for fleet EV application.

Simultaneous breakthroughs in $z$ inc electrode and bifunctional air electrode required. Chances appear to be

1 imited for success. 
TABLE 6.1

\section{(CONT.)}

Battery Type

Zinc-Air

Mechanically

Rechargeable

Circulating

Electrolyte

Zinc-Air

$\stackrel{\text { c }}{\text { Circulating }}$

Slurry

\section{Present Status}

No known

development

efforts.

CGE undertook a substantial development effort. Project has been

terminated. PRI under DOE support

has started

component

research.
Advantages

Long range.

Rapid

refuelability.

Long range.

Rapid

refuelabili-

ty.

Moderate energy

density.

on board

recharging

feasible.
Disadvantages

Low energy

density.

Complex system.

Zinc electrode

problem is

severe.

\section{Prospects}

Complex system with low energy density and limited cycle life due to zinc electrode problems. Potential for success is low.

Complex system. Low energy efficiency. vehicle and load
Attractive system

for both electric

levelling. Does

not suffer from

the zinc electrode

shape change

problem. Can use

air cathodes

developed for

a luminum-air

battery. R\&D

effort at PRI is

in a very early

stage.

Improvements

need to be

demonstrated.

Potential for

success judged

to be good. 


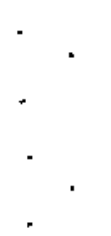




\subsection{SYSTEM DESIGN AND LIFE CYCLE COSTS}

\subsection{GENERAL CONSIDERATIONS}

Generally, complete metal-air battery systems of the type, size and rating needed for the EV application have not been built and tested, and as can be derived from Sections 2.0,3.0, 4.0, and 5.0 the developments have not progressed to a stage where building and testing full-size prototypes is warranted. Considerable additional laboratory R\&D is needed to establish sufficient engineering data to permit the detailed design of a complete system. In some cases not enough is known about a technique, process or component to establish either performance or cost. Thus performance and cost estimates at this time must be considered crude at best; however, these estimates can serve a useful purpose together with recognition of the pertinent technical issues in guiding programs and suggesting alternatives and in projecting the likelihood of achieving success. The discussions that follow are based on a critical review of data and estimates provided by the developers of the system, and where appropriate, conments are made on the effect of changes on these estimates. Experience has shown that as development of a system proceeds, estimates of performance and cost tend to become less optimistic than they were early in the program.

\subsection{ALUMINUM-AIR SYSTEM}

As proposed, the mechanically rechargeable aluminum-air battery system would consist of the battery stack, a blower for all air, an electrolyte circulation pump, a heat exchanger, a carbon dioxide scrubber, moisture exchanger, precipitating device, separating and storing the hydrogillite reaction product, water and electrolyte tanks and a secondary battery to provide power for start-up. The performance projections and most of the development work are centered on the "wedge" cell configuration with a cell active area of $300 \mathrm{~cm}^{2}$. A wedge-shaped aluminum anode is centered between two air electrode cassettes, thus the active electrode area is $600 \mathrm{~cm}^{2}$. Aluminum plates are added manually and aluminum is fed to the cell by gravity as the aluminum is consumed. It is anticipated that in a vehicle the energy content (vehicle 
range) would be limited by the water carried on board with the product $\left.(\mathrm{A})(\mathrm{OH})_{3}\right)$ storage tank being sized so that the product would be removed when the water is replenished. Sufficient aluminum would be carried in place, on board for 3 to 4 water replenishments. Thus water might be added and product removed at 400 to $600 \mathrm{kilometer}$ intervals with aluminum being replenished at 1600 to 3200 kilometer intervals.

The mechanically rechargeable aluminum-air battery operates similar to a fuel cell, i.e., the battery size and cost depend much more heavily on the peak power demands than on the energy content. The peak power demand determines the electrode surface area required which determines the size of the battery stack. The energy content is then determined by the amount of consumables carried on board, i.e., aluminum, water and/or the size of the storage tank for the product.

Since there is insufficient data to prepare detailed designs, Lawrence Livermore National Laboratory has developed an empirical equation for estimating battery weight as follows:

$$
W(\text { in } \mathrm{kg} .)=36 \mathrm{P} / \mathrm{p}+3.5 \mathrm{E} / \mathrm{e}
$$

where $P$ is the peak sustainable power in $k W, P$ is the peak power density in $k W$ per $m^{2}, E$ is the energy content in $k W h$ and $e$ is the gross energy yield of aluminum in $\mathrm{kwh}$ per $\mathrm{kg}$. From this calculation of weight it is possible to estimate battery volume and cost and then to estimate life cycle costs. At this stage of development the problem is the choice of the proper values for $p$ and $e$. Table 7.1 below indicates values which have been proposed by various developers. In light of what is known today about the effect of temperature, electrolyte composition, crystallyzer performance and alloy composition, it is believed the ELTECH proposals are more realistic.

If one uses the ELTECH case 3, the weight of a $100 \mathrm{kWh}, 40 \mathrm{~kW}$ (peak) battery is projected to be $350 \mathrm{~kg} ;$ i.e., $285 \mathrm{Wh} / \mathrm{kg}$ and $114 \mathrm{~W} / \mathrm{kg}$ (peak). Depending on vehicle size, weight and efficiency, this should be adequate for a $400 \mathrm{~km}$ range. Using the LLNL specific gravity estimate of 0.6 , the battery system volume is estimated to be 600 liters; i.e., yield an energy density of $167 \mathrm{Wh} / 1$ and peak power density of $67 \mathrm{~W} / 1$. 
This battery requires $7.4 \mathrm{~m}^{2}$ of air electrode, which ELTECH projects to cost $\$ 240 / \mathrm{m}^{2}$ in production in the 1990 's, resulting in the cost of the air electrode being $\$ 1776$. Allowing an additional cost of $\$ 100 / \mathrm{m}^{2}$ for other items yields a battery cost of $\$ 2516$. LLNL has used a total battery cost of $\$ 208 / \mathrm{m}^{2}$, which is $\$ 977$ less than the current ELTECH air electrode projection.

\section{TABLE 7.1 \\ Aluminum-Air System \\ Proposed Power and Energy Assumptions}

$\begin{array}{ccc}\text { Source } & \begin{array}{c}\mathrm{p} \\ \mathrm{kw} / \mathrm{m}^{2}\end{array} & \begin{array}{c}\mathrm{e} \\ \mathrm{kwh} / \mathrm{kg}\end{array} \\ \text { ELTECH 1985, Case 1 } & 4.5 & 3.6 \\ \text { Case 2 } & 4.95 & 3.9 \\ \text { Case 3 } & 5.4 & 4.2 \\ \text { LLNL 1984, "present" } & 6.5 & 4.4 \\ \text { "1990's" } & 9.0 & 6.5\end{array}$

If the LLNL goal of $9 \mathrm{~kW} / \mathrm{m}^{2}$ is ultimately achieved the battery cost at $\$ 340 / \mathrm{m}^{2}$ would become $\$ 1511$.

ELTECH's current estimated cost for the air electrode is $\$ 2,200 / \mathrm{m}^{2}$ which, while reflecting wholly manual operations, is indicative of the difficulty in achieving the ELTECH's goal of $\$ 240$ per $\mathrm{m}^{2}$ or the more optimistic LLNL goal of $\$ 100$ per $m^{2}$.

The air electrode is expected to be the life limiting component of the aluminum-air battery assuming satisfactory life and reliability of the auxiliary component. Current half-cell tests indicate an air electrode life of about two years with an ultimate goal of extending the life to 4 years. There have been no life tests of cells and it is likely that battery life will be less than that of the air electrode in half cell tests; however, a two-year, 15,000 mile life will be assumed for the battery for life cycle cost estimates.

Depending on vehicle weight, efficiency, driving cycles, etc, a $100 \mathrm{kwh}$ battery will provide a vehicle range of 250 to 400 miles. For purposes 
of the life cycle cost estimate, a range of 325 miles is assumed with product removed and water added two times per month and aluminum added every two months. In addition to these operations, it is expected that other maintenance preparations will be required including replacing the $\mathrm{CO}_{2}$ absorber, replacing or replenishing the electrolyte, periodic flushing and cleaning and perhaps adjusting the $\mathrm{Al}(\mathrm{OH})_{3}$ seeding. Table 7.2 lists the estimated annual costs with operation of this battery.

\section{TABLE 7.2}

Aluminum-Air Battery

Estimated Annual Costs

\begin{tabular}{|c|c|}
\hline Battery Cost $(1 / 2 \times 251 b)$ & $\$ 1,258$ \\
\hline Aluminum Required $(4.2 \mathrm{kWh} / \mathrm{kg})$ & $143 \mathrm{~kg}$ \\
\hline c $\$ 2.00 / \mathrm{kg}$ & $\$ 286$ \\
\hline $\begin{array}{l}\text { Product Removal and Water Addition } \\
(2 \text { manhours/month o } \$ 10 / \mathrm{hr} \text {.) }\end{array}$ & $\$ 240$ \\
\hline $\mathrm{CO}_{2}$ Scrubber replacement $(12 / \mathrm{yr})$ & $\$ 300$ \\
\hline $\begin{array}{l}\text { Adjust Electrolyte, Seed, Flush, etc. } \\
\left.\text { (1 manhour/month o } 10 / \mathrm{hr}_{\text {. }}\right)\end{array}$ & $\$ 120$ \\
\hline Total annual cost $\ldots \ldots \ldots$ & $\$ 2,204$ \\
\hline Delivered $k$ Wh $(24 \times 100)$ & 2,400 \\
\hline Cost per delivered $\mathrm{kWh}$ & \$0.92 \\
\hline Cost per mile $(\Theta 0.25 \mathrm{~kW} / \mathrm{mile})$ & $(9600 \mathrm{mi})$. \\
\hline Cost per mile (@ $0.31 \mathrm{kWh} / \mathrm{mile})$ & $(7742 \mathrm{mi})$. \\
\hline
\end{tabular}

If the optimistic LLNL goals of $9 \mathrm{kw} / \mathrm{m}^{2}, 6.5 \mathrm{Khw} / \mathrm{kg}$ and $\$ 208 / \mathrm{m}^{2}$ are accepted and the annual maintenance costs are assumed to be 50 percent of those shown in Table 7.2, the cost per delivered $\mathrm{KWh}$ is $\$ 0.41$ and the cost per mile is $\$ 0.10$ to $\$ 0.15$.

In the above calculations no credit has been given for the value of the hydrarqillite since there is considerable doubt as to the value of the product. For the case shown in Table 7.2 approximately $410 \mathrm{~kg} \mathrm{of} \mathrm{Al}(\mathrm{OH})_{3}$ is generated annually and for the optimistic case $267 \mathrm{~kg}$ will be generated. 
Assuming a value of $\$ 0.30 / \mathrm{kg}$ for the $\mathrm{Al}(\mathrm{OH})_{3}$, the cost per $\mathrm{kWh}$ is reduced by $\$ 0.05$ in the first case and $\$ 0.033$ in the latter case; i.e., by 5 to 8 percent.

\subsection{IRON-AIR SYSTEM}

As proposed by Westinghouse, an iron-air battery system would consist of the battery stack, a blower, an electrolyte circulation pump, a heat exchanger, a carbon dioxide scrubber and a packed-bed humidifier-dehumidifier. The battery stack is composed of 120 modules in series with each module consisting of 5 cells in parallel. Each cell has a central iron electrode between two bi-functional air electrodes. The active air electrode surface area is $4 \mathrm{~m}^{2}$ per module and a series stack of 120 cells gives a nominal voltage of 100 volts on discharge at $25 \mathrm{ma} / \mathrm{cm}^{2}(4-\mathrm{hr}$ rate). At the time the Westinghouse projection was made (1984) most of the cell testing had been with $100 \mathrm{~cm}^{2}$ cells, no modules had been tested and auxiliary systems were not defined so the projection represents considerable uncertainty. The projection includes provision of a 10 percent energy penalty for operation of the auxiliary systems. The projections for a nominal $40 \mathrm{kWh}$ (4-hr rate) battery are shown in Table 7.3. The $D C-D C$ energy efficiency is not projected directly by the developer; however, calculations based on the most optimistic projections indicate a maximum of 55 percent, while more realistic projections indicate less than 50 percent.

Based on the published data this estimate has to be considered optimistic since it assumes battery performance equivalent to single cell performance, contrary to the usual experience. There also appears to be a discrepancy in the allowance for weight and volume of the auxiliaries since the electrolyte necessary to fill the active volume of the cells is 48 liters $(60 \mathrm{~kg})$, and it is likely that an equivalent quantity of electrolyte would be needed in circulation in the auxiliary equipment. This could require an additional 15-20\% in system weight and volume.

In making cost estimates Westinghouse has used the assumptions in Table 7.4 in lieu of preparing detailed cost estimates since there are still so many unknowns. 


\section{TABLE 7.3}

Iron-Air Battery Characteristics

(Nominal $40 \mathrm{kWh}$ at $10 \mathrm{~kW}$ Discharge Rate)

$2.77 \mathrm{~kg}$
$2.12 l^{2}$
$335 \mathrm{~kg}$
2541
$67 \mathrm{~kg}$
251
$402 \mathrm{~kg}$
2791
$40 \mathrm{kWh}$
$100 \mathrm{Wh} / \mathrm{kg}$
$143 \mathrm{Wh} / 1$
$38 \mathrm{~kW}$
$95 \mathrm{~W} / \mathrm{kg}$
$136 \mathrm{~W} / 1$
$50 \%$ (app.)

In the absence of detailed designs, processes, equipment needs, auxiliary and designs it is not possible to validate these estimates. It does appear that they are optimistic and that the near-term estimate more nearly reflects what might be achieved for the factory cost (not selling price) for an advanced design produced in a mature production facility. To achieve this would require a very significant investment in production facilities after at least 5 years additional development.

Life test data does not exist for iron-air modules and batteries. In half cell tests iron electrodes and air electrodes have demonstrated lives of over 500 cycles. Based on past experience with iron electrodes in nickel-iron batteries there is every reason to expect that the iron electrode will not be the life limiting element in iron-air batteries. Some degradation in performance can be expected as a result of carbonate build-up in the electrolyte, shedding of iron active materials during cycling and increasing non-uniformity on discharge and charge attributable in part at least to nonuniformity of the air electrode. 
TABLE 7.4

Cost Assumptions

\section{Component}

Iron Electrode (per $\mathrm{kg}$ )

Air Electrode (per $\mathrm{m}^{2}$ )

Auxiliaries
Near-Term

$\$ 2.00$

$\$ 30.00$

$\$ 200.00$
Advanced

$\$ 2.00$

$\$ 20.00$

$\$ 200.00$

Applying these assumptions to the above system yields cost estimates as follows:

$\begin{array}{llll} & \frac{\text { System }}{\$ 1800} & \$ / \mathrm{kwh} & \$ / \mathrm{kg} \\ \text { Near-Term } & \$ 1880 & \$ 47 & \$ 4.70(\$ 2.14 / \mathrm{lb}) \\ \text { Advanced } & \$ 1400 & \$ 35 & \$ 3.50(\$ 1.59 / 1 \mathrm{~b})\end{array}$

The bi-functional air electrode is expected to be the life limiting factor in iron-air systems as a result of loss of catalytic activity and structural integrity, non-uniformity of performance, carbonate contamination and eventual flooding of the electrode. Another key issue which has not been addressed is the possibility that catalysts leached from the air electrode and reduce the hydrogen overvoltage on the iron electrode sufficiently to prevent recharge of the iron electrode.

Experience with other battery systems indicates that achieving a life of 500 cycles for an iron-air battery would require achieving a life in half cell tests in laboratory conditions approaching 800 to 1000 cycles and demonstrated module lives in the $600-800$ cycle area. This is approximately 
double the life which has been demonstrated; however, for purposes of life cycle costs, 500 cycles is assumed.

In addition, the life cycle cost will be influenced by the maintenance required. For the iron-air system the following maintenance will be required on a periodic basis:

1. Add make-up water

2. Clean or replace air and electrolyte filters

3. Routing cleaning, tightening and inspection

4. Replace $\mathrm{CO}_{2}$ scrubber medium

5. Discard and replace electrolyte

It is not likely to be economically possible to remove all of the carbon dioxide from the incoming air so the frequency of scrubber and electrolyte replacement are inter-related and also greatly influenced by the total air flow through the system, the size of the scrubber, total quantity of electrolyte and the sensitivity of the iron and air electrodes to $\mathrm{CO}_{2}$. There is insufficient data to make a meaningful estimate; however, some of the data indicates a relatively high sensitivity to $\mathrm{C}_{2}$ contamination by both electrodes.

Based on the assumptions in Table 7.4, and ignoring interest costs, a projection of $\$ 0.30$ per $k$ hh per cycle is obtained for life cycle costs. If the maintenance costs show in Table 6.5 are reduced by $50 \%$, the life cycle costs are reduced to $\$ 0.25$ per $\mathrm{kWh}$ per cycle. Because of the low DC-OC efficiency of the system the life cycle costs are dependent on the $A C$ energy costs, increasing $\$ 0.022$ per $\mathrm{kth}$ for each $\$ 0.01$ increase in $A C$ energy costs. For example, at the residential rates which are $\$ 0.10$ per $\mathrm{kth}$ in some areas, the life cycle cost increases \$0.155.

\subsection{ZINC-AIR SYSTEMS}

The low rate zinc-air primary battery system has long been known as provided the lowest cost $D C$ energy of any battery system. As pointed out in Section II there have been many attempts in the last 25 years to try to develop high rate rechargeable zinc-air batteries. However, problems with dendrite formation zinc densification and shape change of the zinc electrode on recharge 
along with the short life of bi-functional air electrodes have prevented the development of zinc-air batteries with adequate life and performance. To avoid the problems developers have turned to slurry zinc-air battery systems in which the zinc is supplied to the cell in the circulating electrolyte as zinc dust in suspension of plated on suspended lightweight plastic beads and the reaction product carried from the cell in solution or in suspension. The spent electrolyte containing the zincate reaction product is stored in a holding tank on-board and recharging could be performed onboard in a separate electrolysis system or off-board at a control station. With off-board recharging, refueling could be accomplished quite quickly by simply pumping of the spent electrolyte and pumping in fresh zinc slurry.

CGE in France was the most successful of the developers of slurry zincair systems. At the time the CGE program as terminated in 1975, their zincair system performance was $82 \mathrm{w} / \mathrm{kg}$ and $84 / \mathrm{wh} / \mathrm{kg}$ for a $300 \mathrm{~kg}$ battery in a tubular geometry. Foller has recently prepared a revised estimate, of performance for a $300 \mathrm{~kg}$ slurry zinc-air battery based on improvements on the CGE technology, and projects a $124 \mathrm{~W} / \mathrm{kg}$ and $91 \mathrm{Wh} / \mathrm{kg}$ for on-board recharging and $124 \mathrm{w} / \mathrm{kg}$ and $99 \mathrm{Wh} / \mathrm{kg}$ for off-board recharging. Cost estimates are not available; however, the zinc-air systems projected would require about $9 \mathrm{~m}$ of air electrode or 2160 at the ELTECH projection of $\$ 240 / \mathrm{m}^{2}$. Thus, the cost for the slurry zinc-air system is expected to be in the same ball-park as other metal-air systems; however, it does appear to offer the promise of rapid refueling in the primary version without the crystallizer/separator problems associated with the aluminum-air system. Depending on the technique used for regenerating the slurry the $D C-D C$ energy efficiency for the zinc-air system will probably be $50 \%$ or less.

The zinc-coated plastic beads may offer the opportunity for increases in specific energy and specific power; however, this is at such an early stage in development that costs cannot be projected.

The other problems of the slurry zinc-air system including electrolyte maintenance, $\mathrm{CO}_{2}$ scrubbing, thermal control and flushing are expected to be similar to those for the other metal-air systems. 


\section{TABLE 7.5}

Iron-Air Battery $(40 \mathrm{kWh})$

Life Cycle Cost Assumptions

Battery Cost

Cycle Life

Energy Delivered/Cycle

OC Recharge Energy/Cycle

Charger Costs

Charger Efficiency ( $A C-O C$ )

$A C$ Energy Required

AC Costs $\$ 0.03 / \mathrm{kwh}$

Routine Maintenance and Water Make-Up

(1 man hour/week o\$10/hr.)

Filter replacement $4 /$ year

Replace $\mathrm{CO}_{2}$ Scrubber 4/year

Replace Electrolyte 4/year
$\$ 1880$

500 cycles

$32 \mathrm{kWh}$

$64 \mathrm{kWh}$

$\$ 150 /$ year

$90 \%$

$17,800 \mathrm{kWh} / \mathrm{yr}$.

$\$ 533.33 /$ year

$\$ 500.00 /$ year

$\$ 80 /$ year

$\$ 100 /$ year

$\$ 120 /$ year
Maintenance Costs

As Stated

$\$ 2423 /$ year

$8000 \mathrm{kwh}$

$\$ 0.30$
Reduced 50\%

$\$ 2023 /$ year

$8000 \mathrm{kWh}$

$\$ 0.25$

\subsection{GENERAL COST CONSIDERATIONS}

1. Air Electrode. As can be seen from the above discussions the cost of operating a metal-air battery is very dependent on the cost and life of the air electrode. Since these systems operate in alkaline electrolytes at about the same temperature and air flow, it is reasonable to expect that the current and power densities at the air electrode are about the same for all of the systems. It is also reasonable to expect that the air electrode life 
will be about the same in all systems for mono-functional air electrodes, assuming the absence of air electrode poisons from the rest of the system. It is expected that the bi-functional air electrode will have a shorter life than a mono-functional electrode, will cost more and may have lower performance. It also seems likely that metal-air developers will ultimately gravitate to the best available air electrode technology.

Thus for a given battery power level the air electrode cost will be determined by the polarization curve for the anode. The data from the developers current-state-of-the-art indicates about $1 / 3$ more air electrode area will be required for zinc-air compared to aluminum-air; i.e., only 50 percent of the penalty expected on a theoretical basis. Iron-air would require at least double the Al-air electrode area with the Westinghouse estimate noted above requiring $48 \mathrm{~m}^{2}$ of air electrode or about 6 times that.

Significant performance improvements have been suggested for the aluminumair system specific power which may increase the aluminum-air advantage over slurry zinc-air however, there appear to be opportunities for improvements in the latter system also.

2. Maintenance. There is little reason to believe that the maintenance problems will differ greatly between the aluminum-air and slurry zinc-air systems. Both will require $\mathrm{CO}_{2}$ scrubbing, water make-up, electrolyte control, themal control and routine cleaning and flushing. If operated as primary systems both will require handling similar quantities of products and the associated infrastructure. The slurry system has an advantage in not requiring the crystallyzer/apparator system required by aluminum-air.

3. $D C-D C$ Energy Efficiency. This can generate considerable debate among developers since the details of the regeneration of the anode reactant are not established for either aluminum-air or slurry zinc-air. Since these are flow systems with various auxiliary and parasitic losses and will require handling of significant quantities of reaction products, it seems likely that the $D C-D C$ energy efficiency will be less than $60 \%$, and in fact may not exceed $50 \%$ until a well developed recycling system is established. 



\subsection{CONCLUSIONS AND RECOMMENDATIONS}

With continued development, some of the metal/air batteries have the potential of meeting the requirements of a general purpose electric vehicle, having the range and performance and rapid refuelability compared to that of an ICE vehicle. The aluminum-air battery and the circulating slurry zinc-air battery fall in this category. The iron-air battery has the potential of being a low cost, reliable battery, for limited range fleet vehicle application however, a significant breakthrough in bi-functional air electrode technology is needed.

The metal-air batteries generally have lower electric to electric conversion efficiencies compared to some of the other advanced secondary batteries. For example, a sodium-sulfur battery is expected to have an efficiency of $65 \%$ compared to $42 \%$ for the circulating slurry zinc-air and $30 \%$ for the aluminum-air battery. Thus research on metal-air batteries cannot be justified on efficiency alone, rather the potential for higher performance over other advanced secondary battery systems has to be cited as the primary advantage. The overall coal to road efficiencies of both the circulating slurry zinc-air and the aluminum-air batteries have the potential of being better than the coal to road efficiencies expected from ICE engines operating on synthetic fuels.

The two promising metal-air batteries are complex systems when considered against other advanced secondary batteries. This raises the issue of reliability and vehicle packaging. However, it should be borne in mind that the presently used conventional ICE engine is also a very complex system which has evolved into a quite reliable system over many years. At the present state of research it is rather difficult to predict with any confidence the potential reliability of the promising metal-air systems. Rather R\&D should continue on these systems keeping in mind that potential system design must address the reliability and vehicle packaging issue.

Commercialization of either the circulating slurry zinc-air battery or the aluminum-air battery as the power source for a general purpose electric vehicle will require the evolution of a considerable infrastructure to support these technologies. There is no question that this infrastructure will be 
more complex than with EV's operating with advanced secondary batteries. No attempt has been made in this assessment to ascertain through a survey of the automotive and/or the gasoline industry as to how difficult this issue could be. However, some conversation with researchers in these industries indicate that if the expected performance of these metal-air batteries are realized and if there is a customer demand for a general purpose ICE vehicle, market forces will address the infrastructure issue so long as it is economical. At this stage of research it is impossible to realistically estimate the cost associated with developing such an infrastructure.

Estimates of life cycle costs for the circulating slurry zinc-air and the aluminum-air battery are preliminary at this time. However, in both systems it appears that the air-cathodes are the most significant cost item. Longer life ( 14 years) and lower costs would be essential for these metal-air batteries to be commercially successful and R\&D to accomplish this goal must continue. Overall, it appears that the life cycle cost of the aluminum-air system would be higher than the circulating slurry zinc-air system. This is partly due to the anticipated higher cost of the aluminum alloys used. Efforts to develop a lower cost, high performance aluminum anode must therefore be a very high priority. However, the anticipated higher cost of the aluminum-air system must be compared with the potentially higher energy density expected from this system. The circulating slurry zinc-air has lower cost but will also have a lower energy density compared to the aluminum-air systen. No clearcut winner can be assigned on the basis of life cycle costs at this time.

Based on the results obtained to date, it appears that good progress has been made in developing the key components of the aluminum-air battery. The aluminum alloys and the air cathodes are showing performance close to the targeted performance. Research must continue on these components with an objective to reduce the costs without sacrificing performance. The electrolyte management system in the aluminum-air battery is critical to the successful operation of the battery. Progress has been made in understanding the product separation kinetics, however, a successful integration and operation of an aluminum-air battery with an electrolyte management system has not been accomplished. The coupled operation of the two components is strongly recommended to prove the technical feasibility of the aluminum-air battery. 
Research on the circulating slurry zinc-air battery has been underway with DOE support only for the last several months. The Technology Base Research Lead Center in conjunction with the contractor (Pinnacle Research Institute) has identified the critical technical issues involved. Very little experimental results are available at this time to asses the progress made. If these technical issues are successfully resolved, this battery system will be a strong competitor to aluminum-air as the power source for a general purpose electric vehicle. In addition, attention must be given to the fact that a circulating slurry zinc-air battery can be an attractive candidate for stationary energy storage. This battery could compete very well in terms of performance with other flow batteries under development for load leveling such as zinc-bromine and zinc-ferricyanide.

Research and development on bi-functional air electrodes should be encouraged. Emphasis on this area must be placed on developing efficient longlived catalysts and substrates. The recent progress made at Lawrence Berkeley Laboratories on corrosion resistant carbon substrates should be vigorously pursued. A breakthrough in bi-functional air electrode technology will make the iron-air battery a very promising battery for some electric vehicle applications. 


\section{REFERENCES}

1. Maimoni, A., March, 1985. "Aluminum-Air Power Cel1, A Progress Report." LLNL, UCRL -92281 .

2. Littauer, E.L. and J.F. Cooper. 1984. "Metal/Air Batteries" in Handbook of Batteries and Fuel Cells. D. Linden, ed. McGraw Hill, New York.

3. Carson, H.N. and Kent, C.E. 1966. "The Magnesium/Air Cell" in Power Sources, D.H. Collins, ed., p. 119.

4. Cooper, J.F. and Hosmer, P.K. October 1977. "The Behaviour of Calcium Electrodes in Aqueous Electrolytes." Electrochemical Society Fall Meeting.

5. Bauman, H.F. and Adans, G.B. October 1977. "Lithium-Water-Air Battery for Automotive Propulsion." Final Report for Period October 28, 1976 to September 28, 1977. Lockheed Palo Alto Research Laboratory, C00/1262-1.

6. Momyar W.R. and Littauer, E.L. August 1980. "Development of a LithiumWater-Air Primary Battery." Proceedings of the Fifteenth Intersociety Energy Conversion Engineering Conference. p. 1480, Seattle, WA.

7. Klein, M., Viswanathan, S. December, 1986. "Zn-Air Battery R\&D; Zn-Air Engineering Analysis for Electric Vehicles "Task 3, Final Report, LBL-22662.

8. Duperray, G., Marcellin, G., and Pichon, B. 1981. Power Sources VIII, Ch. 32, p. 489, Academic Press.

9. Fleischer, A. 1968. "Survey and Analysis on Metal/Air Cells." Technical Report, AFAPL-TR-68-6.

10. Witherspoon, R., Zeitner, E., and Schulte, H. August 1971. Proceedings of the Sixth Intersociety Energy Conversion Engineering Conference. Boston, MA, p. 96.

11. Bryant, W.A., Liu, C.T.,Buzzelli, E.S., 1978, "Iron-Air Battery Characteristics," Proc. 29th Power Sources Symp., Electrochemical Society, Pennington, N.J., p. 152. 
12. Ross Jr., P.N. 1987, "A New Concept In An Electrically Rechargeable ZincAir Alkaline Battery", Presented at the 8th DOE Battery and Electrochemical Contractors Meeting, Tysons Corner, Va., p. 276.

13. Ikeda, H., Furukawa, N., and Ide, M. April 1979. "Metal-Air Batteries", paper presented at Journal of the Congress of the American Chemical Society Japan, Honolulu.

14. Foller, P.C., 1986, "Improved Slurry Zn/Air Systems as Batteries for Urban Vehicle Propulsion." J. Appl. EChem., 16 No. 4, 527.

15. Littauer, E.L. and J.F. Cooper. 1984. "Metal/Air Batteries" in Handbook of Batteries and Fuel Cells. D. Linden, ed. McGraw Hill, New York, Chapter 30.

16. Sierra-Alcazar, H.B., Nguyen, P.D. November, 1987. "Slurry Zinc Air Battery Research and Development." Extended Abstracts: Eighth Battery and Electrochemical Contractors' Conference." Vienna, VA, p. 270.

17. Sierra-Alcazar, H.B., Nguyen, P.D. August, 1987. "Additives to Increase the Discharge Capacity of the Moving Bed Zinc/Air Battery." 22nd Intersociety Energy Conversion Engineering Conference." Paper No. 879397, Philadelphia, PA, p. 1033.

18. Baba, H. 1971. "A New Zinc-Air Fuel Battery System." Society of Automotive Engineers. Warrendale, PA 710327 Automotive Engineering Conference, Detroit, p. 930.

19. Appleby, A.J., Jacquelin, J., and Pompon, J.P. 1977. SAE Paper 770381, Trans Automotive Engineering Conference, Detroit.

20. Appleby, A.J. and Jacquier, M. 1976. "The CGE Circulating Zinc/Air Battery: A Practical Vehicle Power Source." J. Power Sources 1, 17.

21. Appleby, A.J., Jacquelin, J., and Pompon, J.P. May 1977. "Current Status of the CGE Circulating Zinc-Air Vehicle Battery." Paper No. 316, Electrochemical Society Spring Meeting, Philadelphia.

22. Sierra-Alcazar, H.B., Nguyen, P.D. October, 1987. "Technology Base Research on the Slurry Zinc/Air Battery." 172nd Meeting of the Electrochemical Society, Inc., Honolulu, Hawaii. 
23. Evans, J.W., Huh, T. January, 1986, "Electrical and Electrochemical Behavior of Fluidized Bed Electrodes Part II. Effective Bed Resistivities." LBL-20841.

24. Sierra-Alcazar, H.B., Nguyen, P.D. October, 1987. "Performance of $2 n$ Coated Polymeric Bead and $\mathrm{Zn}$ Powder in a Moving-Slurry $\mathrm{Zn} /$ Air Battery: A Comparison." 3rd Battery Material Symposium, Hawaii.

25. Behrin, E. and Cooper, J. 1981. "Metal-Air Battery Research and Development." Report No. UCID 19440, Lawrence Livermore National Laboratory.

26. Bohnstedt, W. 1980, J. Power Sources, 5, 245.

27. Sierra-Alcazar, H.B., Nguyen, P.D. November, 1987. "Slurry Zinc Air Battery Research and Development." Presented at the 8th DOE Battery and Electrochemical Contractors Meeting, Tysons Corner, Va., p. 270.

28. Cooper, J. F., Littauer, E. L. 1978, "Mechanically Rechargeable MetalAir Batteries for Automotive Propulsion", 13th 1ntersociety Energy Conversion Engineering Conference, UCRL-811768.

29. Littauer, E. L. 1981, "Aluminum-Air Battery Hardware Development at Lockheed Missiles and Systems Co., "Proceedings 4th U.S. DOE Battery and Electrochemical Contractors Conference.

30. Despic, E. R., Milanovic, P. D. 1979, Recueil des Travaux de L'Institut des Sciences Techniques de L'Acadamie Serve des Science et Arts, Vol. 12. No. 1 .

31. Appleby, A.J. and Jacquier, M. 1976. "The CGE Circulating Zinc/Air Battery: A Practical Vehicle Power Source." J. Power Sources 1, 17.

32. 1987, "Aluminum-Air Battery Development", Final Report to Lawrence Livermore National Laboratory, Contract No. 1806205, Section VIIIC.

33. 1987. "Aluminum-Air Battery Development", Final Report to Lawrence Livermore National Laboratory, Contract No. 1806205, Section V1.C.

34. 1985, "Aluminum-Air Battery Development", Final Report to Lawrence Livermore National Laboratory, Contract No. 5033001. 
35. Yeager, E. 1986, Electrochimica Acta, 29, 1527.

36. Maimoni, A., Muelder, S. A., Hui, H. C. 1985, "Aluminum-Air Power Cell: the M-4 Assembly and Initial Tests", UCID-20495.

37. 1987, "Aluminum-Air Battery Development", Final Report to Lawrence Livermore National Laboratory, Contract No. 1806205, Section VIIB.

38. Rudd, E. J. 1987, "Aluminum-Air Battery Development", Presented at the 8 th DOE Battery and Electrochemical Contractors Meeting, Tysons Corner, Va.

39. Wheeler, D.J., April 1986, "Air Systems Research Review Meeting." Cleveland, ohio. 


\section{Distribution}

No. of

Copies

Kenneth $W$. Klein

United States Department of Energy Office of Electric Energy Systems

Forrestal Building, CE-32

1000 Independence Ave., S.W.

Washington, D.C. 20585

Albert R. Landgrebe

United States Department of Energy

Forrestal Building, CE-32

1000 Independence Ave., S.W.

Washington, D.C. 20585

Russell Eaton III

United States Department of Energy

Forrestal Building, CE-32

1000 Independence Ave., S.W.

Washington, D.C. 20585

James E. Quinn

United States Department of Energy

Forrestal Building, CE-32

1000 Independence Ave., S.W.

Washington, D.C. 20585

Pandit Patil

United States Department of Energy

Office of Transportation Systems

Forrestal Building, CE-152

1000 Independence Ave., S.W.

Washington, D.C. 20585

10 DOE Technical Information Center

James W. Evans

Lawrence Berkeley Laboratory

Department of Material Science

University of California

Berkeley, CA 94720

Frank McLarnon

Lawrence Berkeley Laboratory

University of California

1 Cyclotron Road

Berkeley, CA 94720
No. of

Copies

Kim Kinoshita

Lawrence Berkeley Laboratory

$90 / 3026$

1 Cyciotron Road

Berkeley, CA 94720

Philip N. Ross

Lawrence Berkeley Laboratory

$62 / 203$

1 Cyclotron Road

Berkeley, CA 94720

Nicholas J. Magnani

Sandia National Laboratories 2520

P.0. Box 5800

Albuquerque, N.M. 87185

Paul C. Butler

Sandia National Laboratories 2520

P.0. Box 5800

Al buquerque, N.M. $87185-5800$

Richard R. Bassett

Sandia National Laboratories 2520

P.0. Box 5800

Albuquerque, N.M. 87185-5800

Eric J. Rudd

ELTECH Research Corporation

625 East Street

Fairport Harbor, $\mathrm{OH} 44077$

Hector Sierra

Pinnacle Research Institute

10432 North Tantau Avenue

Cupertino, CA 95014

James Huff

Electronics Division

Los Alamos National Laboratory

MS D429

P.0. Box 1663

Los Alamos, N.M. 87545 
No. of

Copies

\author{
John Dunning \\ General Motors Research \\ Laboratories \\ Electrochemistry Department \\ RCEL Building \\ Warren, MI 48090-9058 \\ Gary Henriksen \\ EG\&G Idaho \\ P.0. Box 1625 \\ Idaho Falls, ID 83415 \\ David Zuckerbrod \\ Westinghouse Research \& \\ Development Center \\ 1310 Beulah Road \\ Pittsburgh, PA 15235 \\ Robert W. Fenn \\ ELTECH Research Corporation \\ 625 East Street \\ Fairport Harbor, OH 44077
}

\title{
ONSITE
}

4 DOE Richland Operations Office

J. J. Sutey/D. R. Segna (3)

64 Pacific Northwest Laboratory

L. L. Fassbender

C. H. Imhoff

R. C. Adams

R. G. Rivera

J. R. Divine

P. E. Hart

D. R. Brown

R. K. Sen (25)

S. L. Van Voorhees (25)

Publishing Coordination (2)

Technical Information (5) 